\title{
المجلس الاستوري الجزائري بين الاستقلالية والتبعية في ظل التعديل الاستوري 2016
}

The Algerian Constitutional Council between independence and subordination under the constitutional amendment 2016 تاريخ الاستلام : اليوم/الثهر/السنة ؛ تاريخ القبول : اليوم/الثهر/السنة

\begin{tabular}{|c|c|c|}
\hline & \multicolumn{2}{|r|}{ ملخص } \\
\hline 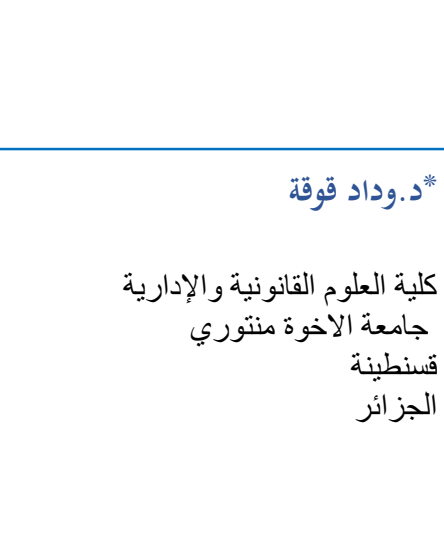 & \multicolumn{2}{|c|}{ 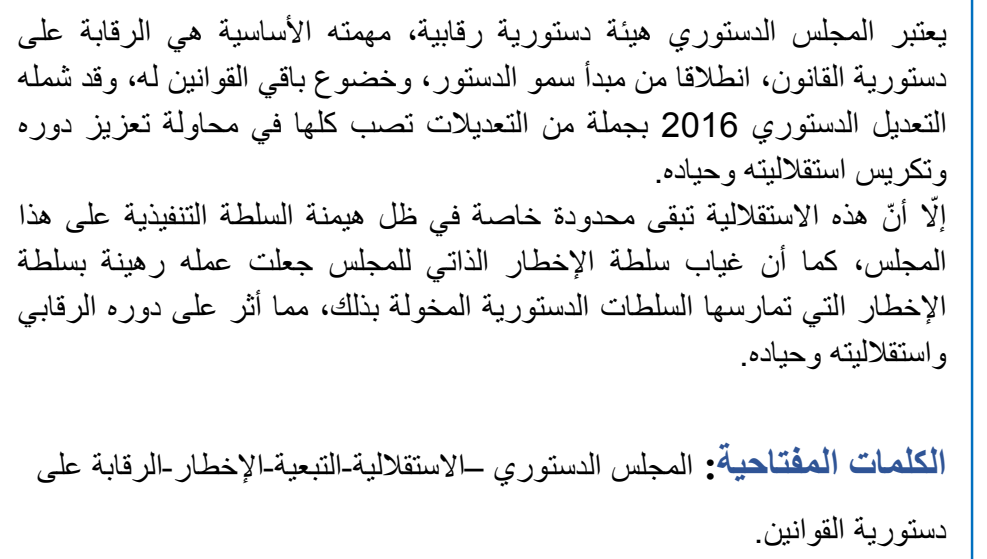 } \\
\hline $\begin{array}{l}\text { Abstract } \\
\text { The Constitutional Council i } \\
\text { organism, Whose primary tas } \\
\text { constitutionality of the law } \\
\text { principle of the supremacy of } \\
\text { And the subordination of the } \\
\text { was amended by the Constitut } \\
2016 \text { with a number of amend } \\
\text { strengthen its role An } \\
\text { independence and neutrality. } \\
\text { However, this autonomy re } \\
\text { particular Under the dominatio } \\
\text { authority On this Council, A } \\
\text { self-notification authority, its } \\
\text { notification authority exercised } \\
\text { constitutional authorities , W } \\
\text { oversight role, independence an }\end{array}$ & $\begin{array}{l}\text { constitutional } \\
\text { to oversee the } \\
\text { Based on the } \\
\text { Constitution, } \\
\text { her laws, And } \\
\text { al Amendment } \\
\text { nts, trying to } \\
\text { to devote its } \\
\text { ins limited in } \\
\text { the executive } \\
\text { the absence of } \\
\text { the competent } \\
\text { theutrality } \\
\text { Independenc } \\
\text { atrol of the }\end{array}$ & $\begin{array}{l}\text { Résumé } \\
\text { Le Conseil constitutionnel est un organisme } \\
\text { constitutionnel dont la tâche principale est de } \\
\text { contrôler la constitutionnalité de la loi, sur la base } \\
\text { du principe de la suprématie de la Constitution, et } \\
\text { la subordination des autres lois, et a été amendé } \\
\text { par l'amendement constitutionnel de } 2016 \text { avec un } \\
\text { certain nombre des amendements, en essayant de } \\
\text { renforcer son rôle et de consacrer son } \\
\text { indépendance et sa neutralité. } \\
\text { Cependant, cette autonomie reste particulièrement } \\
\text { limitée. Sous la domination du pouvoir exécutif sur } \\
\text { ce conseil, et l'absence d'autorité d'auto- } \\
\text { notification, son travail est lié à l'autorité de } \\
\text { notification exercée par les autorités } \\
\text { constitutionnelles compétentes, ce qui a affecté son } \\
\text { rôle de neutralité. } \\
\text { Mots clés: Conseil constitutionnel; Indépendance; } \\
\text { Subordination ;Notification ; Contrôle de la } \\
\text { constitutionnalité des lois. }\end{array}$ \\
\hline
\end{tabular}

* Corresponding author, e-mail: gougaouided@outlook.com 


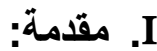

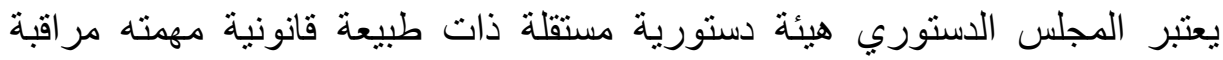
دستورية القوانين والسهر على احترام الدستور، وهو ما نصت عليه المادة 182 من

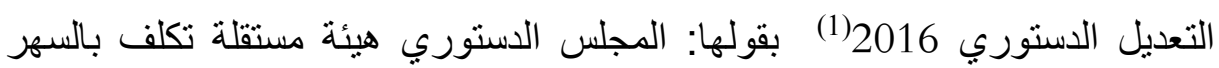

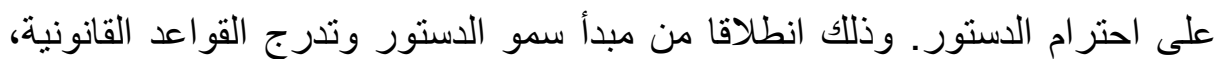

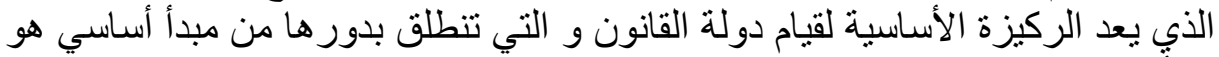

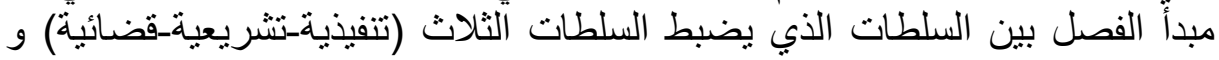

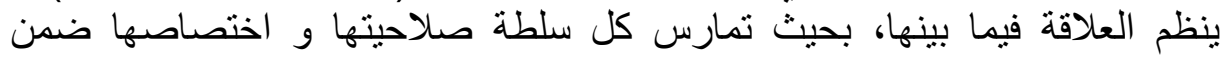

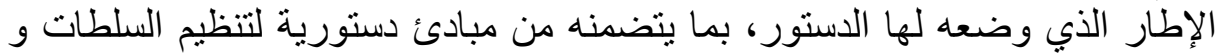
إيجاد التوازن بينها. مما يقتضي حتما توفير قدر من الرقابة ونائ و الحماية حفاظا على التوازن بين جميع هذه السلطات.

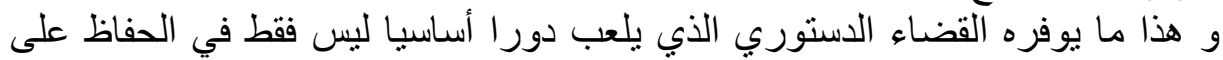

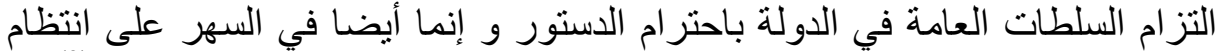

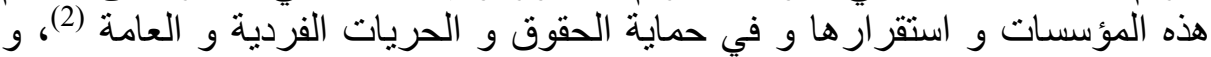

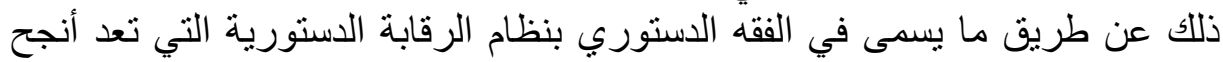

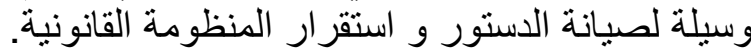
لذا نجد المشرع الجزائري قد أورد المجلس الدستوري في التعديل الدستوري 2016

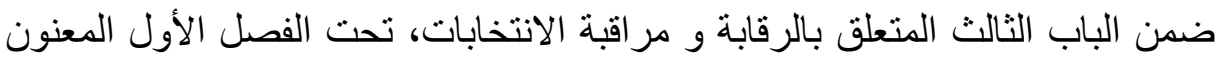

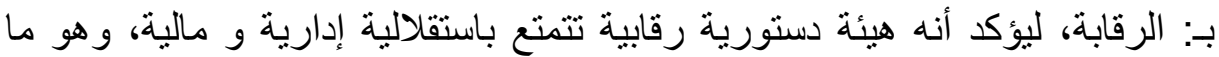

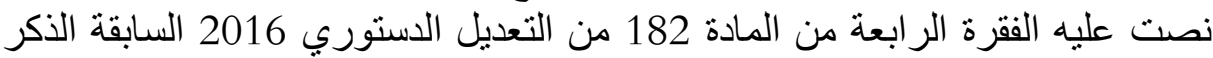

و التي تتص علي: "يتمتع المجلس الدستوري بالاستقلالية الإدارية و المالية."

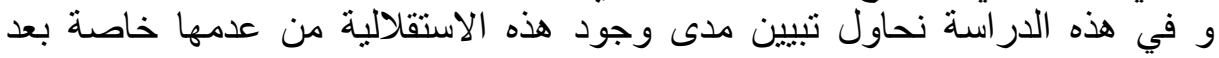

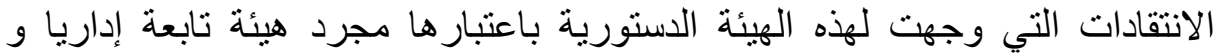
سياسيا للسلطة التنفيذية، و ذلك عن طريق القيود التي كرسها دستور 1989 و التعديل الاستوري 1996 على هذه الهيئة من خلال تشكيل المجلس التابعة إداريا و سياسيا

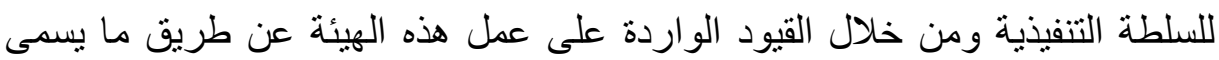

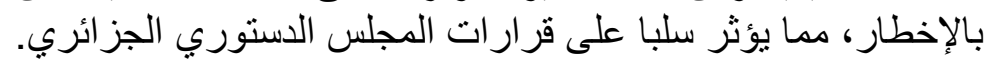

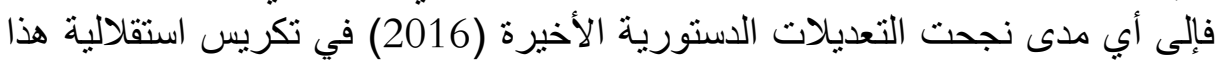

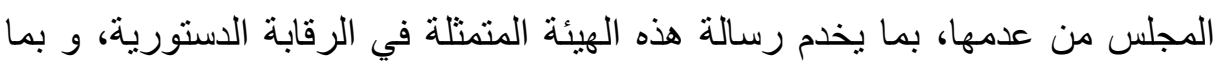

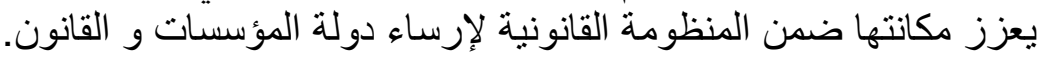

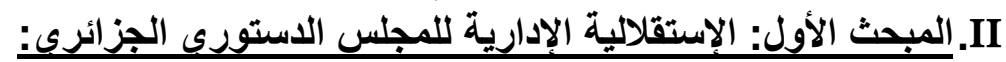

إن طبيعة صلاحية المجلس الاستوري، و أهمية قراراته التي يمكن أن بتخذها كنوع

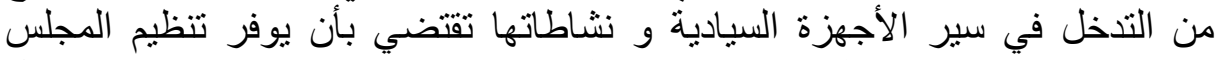

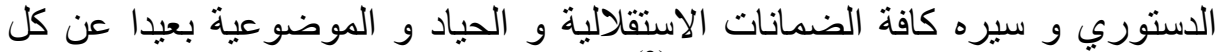

الاعتبار ات الذاتية و الأهو اء السياسية. حيث يتوقف نجاح أي هيئة دستورية في الاضطية الألاع الفعال بالصلاحيات الموكلة لها،

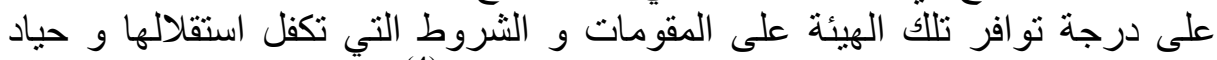

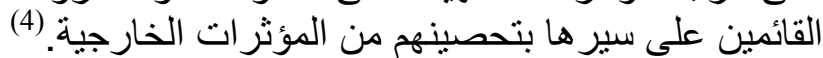

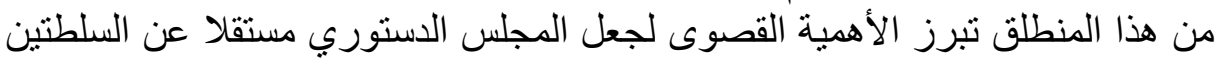


التشريعية و التنفيذية اللتين يتولى مهمة رقابة نشاطهما و الحيلولة دون فرضها لأحكام الدستور.

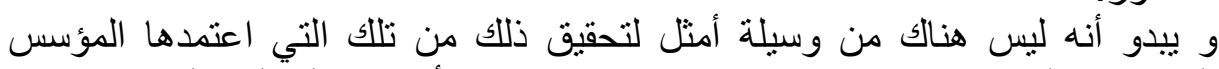

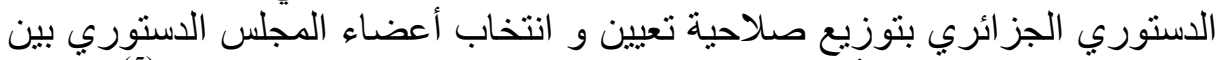

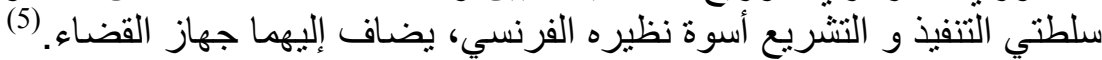
حيث عزز التعديل الاستوري 2016 مظاهر استقلالية المجلس الدستوري من خلاف التهان استقلالية عضوية و أخرى وظيفية تكفل أداءه بشكل فعال، إلا أنها تحمل في طياتها

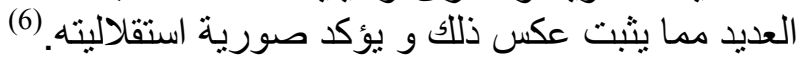

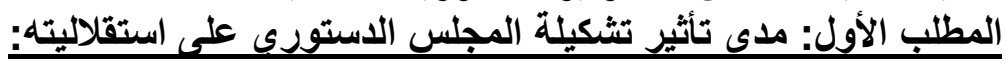

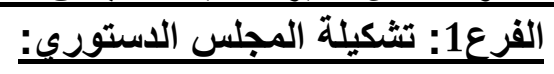

كان المجلس الدستوري في التعديل الدستوري (1996 يتكون من تسعة أعضاء، حيث الثينوين

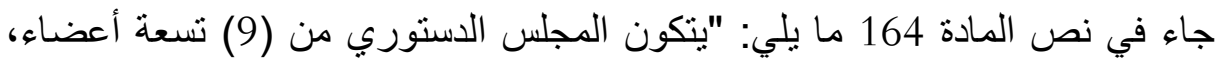
تلاثة (3) أعضاء من بينهم الرئيس يعينهم رئيس الجمهورية و إثنان (2) ينتخبهما

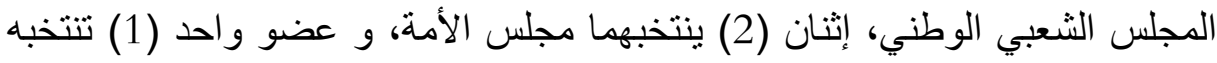
المحكمة العليا، و عضو و احد (1) ينتخبه مجلس الدولة").

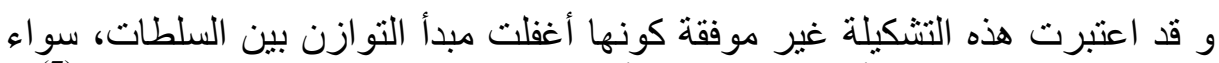

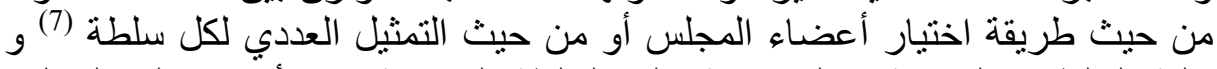

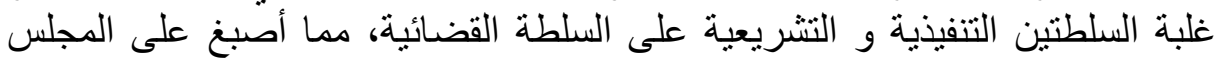

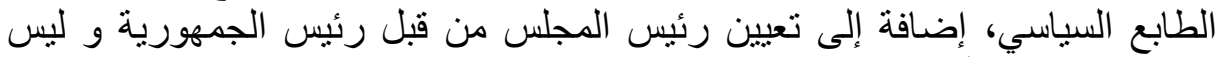

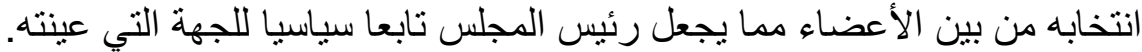

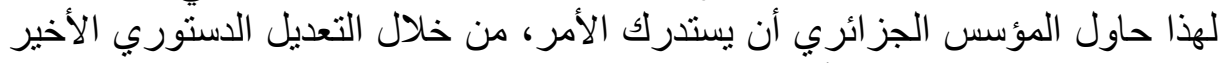

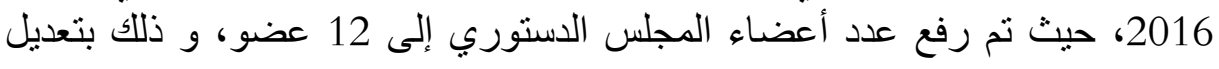

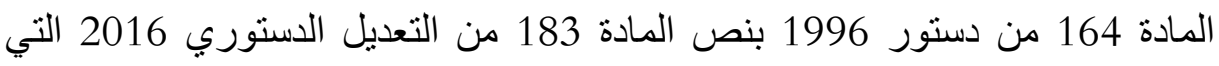

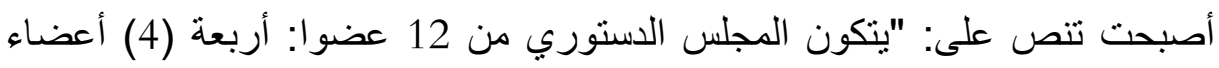
من بينهم رئيس المجلس و نائب رئيس المجلس يعينهم رئيس الجمهورية، و إثنان (2) ينتخبهما المجلس الثعبي الوطني، و إثنان ينتخبهما مجلس الأمة، و إثنان الثنان تنتخبهما

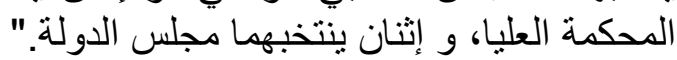

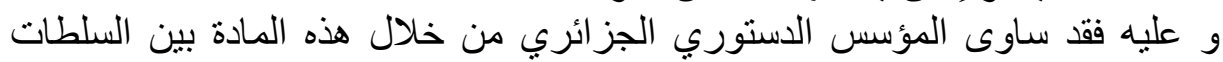

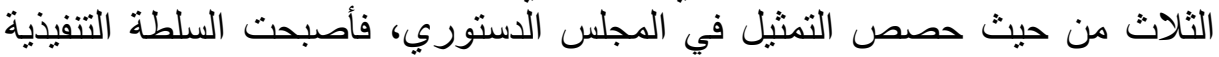

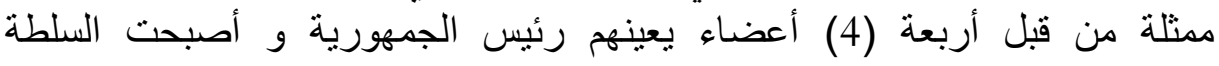

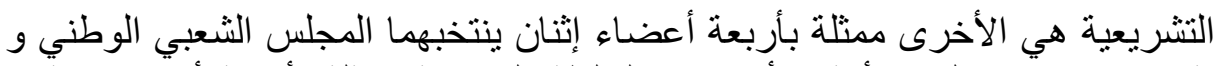

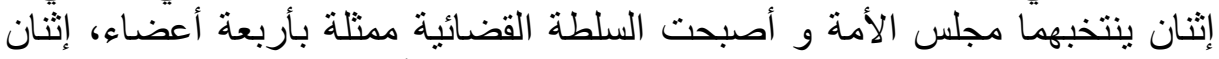

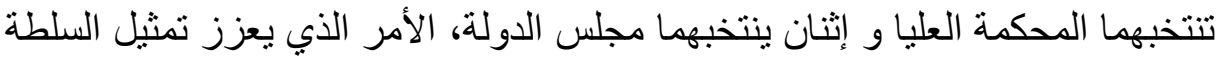

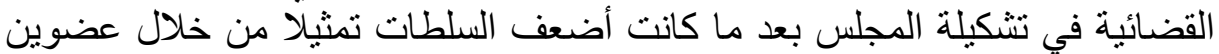

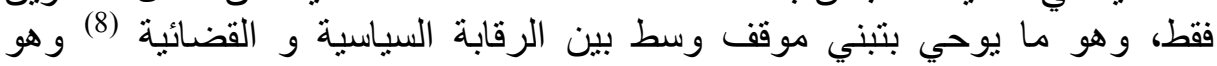

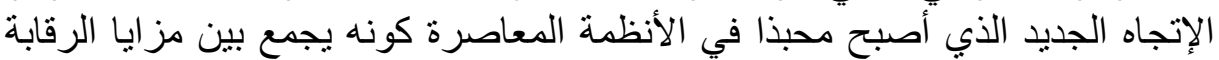

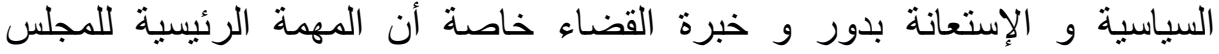

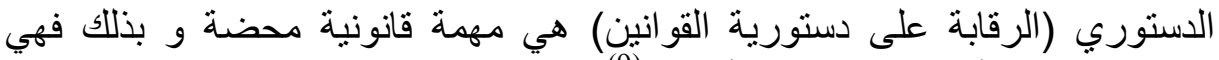

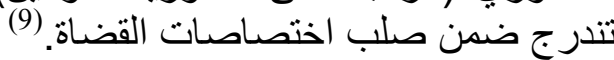

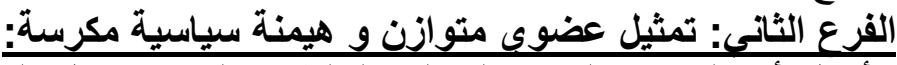

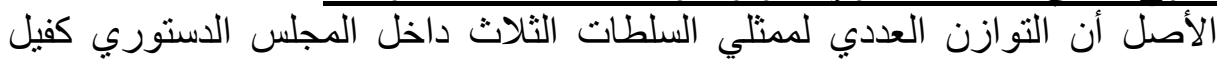


بضمان عدم هيمنة إحدى السلطات على تسيير المجلي أو التأثير على اتخاذ القرار فيه

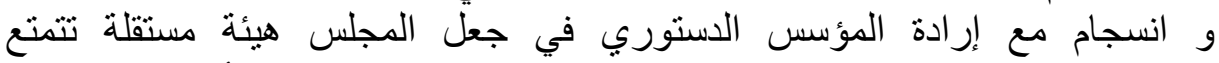
بالاستقلالية الإدارية و المالية (م 182/ فقرة 3)، غير النه و ون من جهة أخرى من خلال

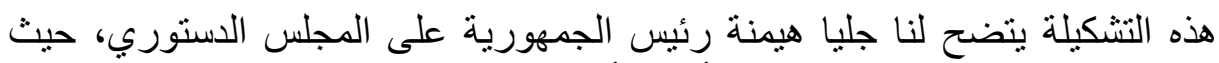

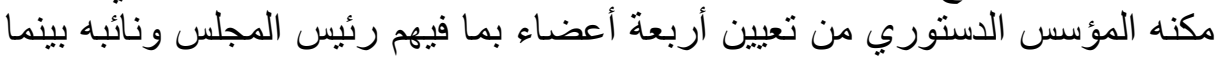
تقوم السلطة التشريعية و السلطة التنفيذية بانتحاب أربعة أعضاء أعضاء لكل منهما و هنا نؤكد

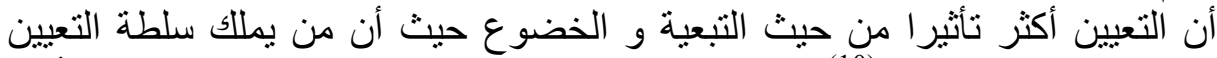

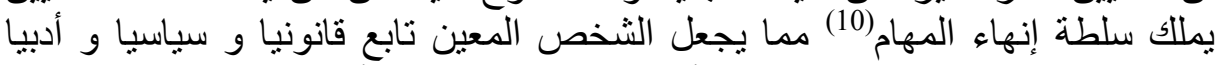

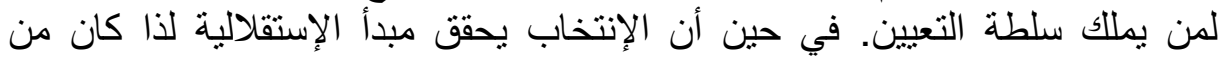

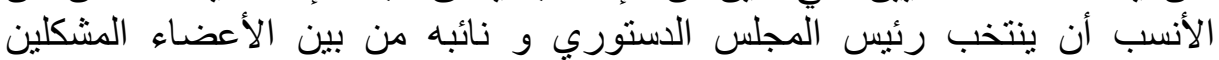

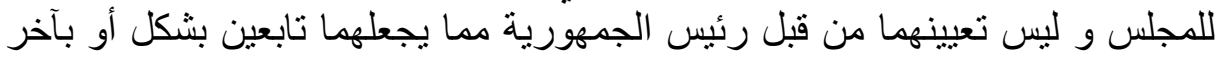

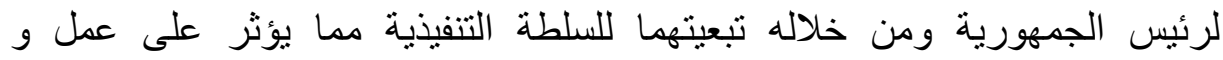
إستقلالية المجلس الدستوري.

أضف إلى ذلك أنه تمت دسترة ترجيح التهائ صوت رئيس المجلس الدستوري في حالة

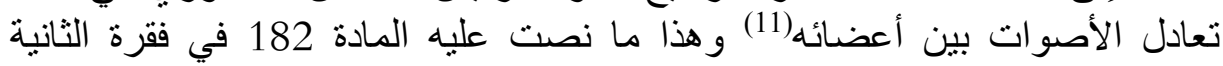

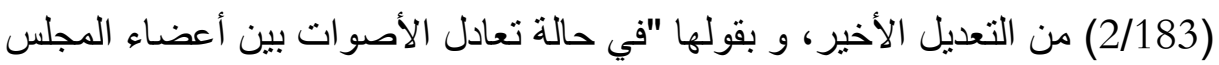

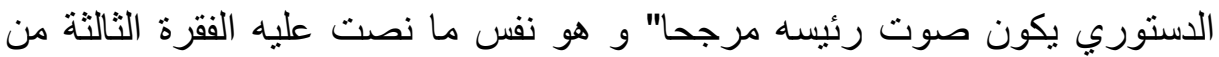

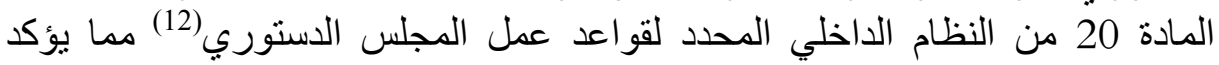
تفوق السلطة التنفيذية على السلطتين التشريعية و القضائية في السيطرة و توجيه

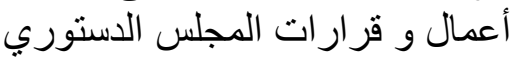

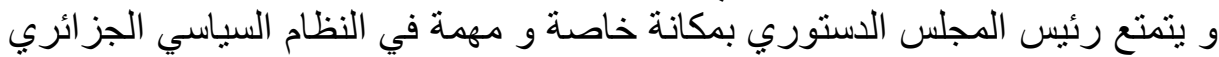

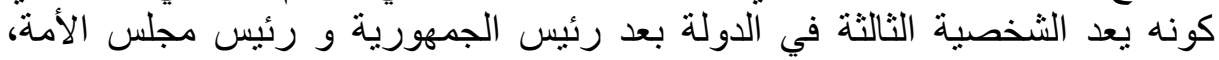

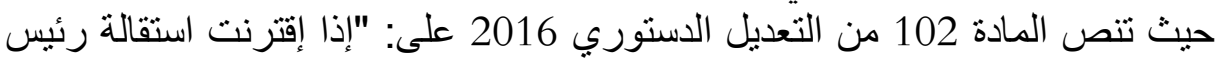
الجمهورية أو وفاته بشغور رئاسة مجلس الأمة .... يتولى رئيس المجلس الدستوري

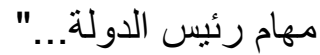

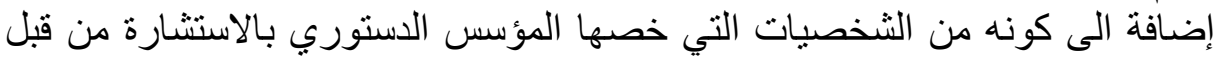

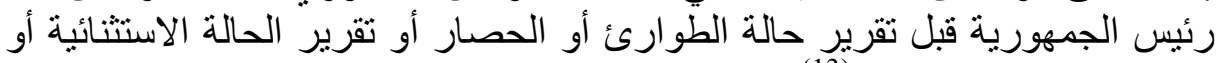

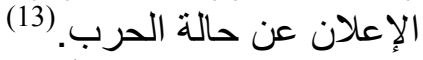

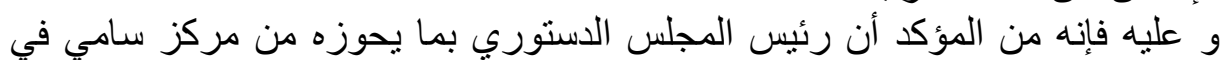

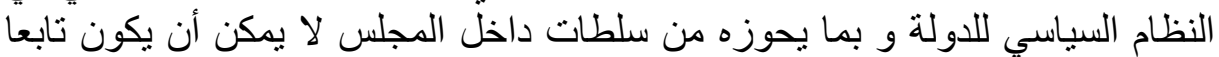

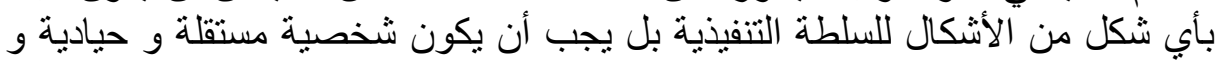

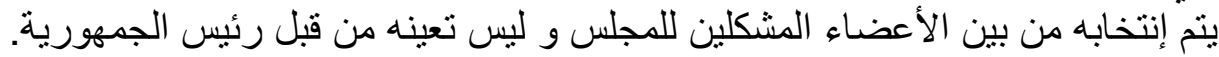

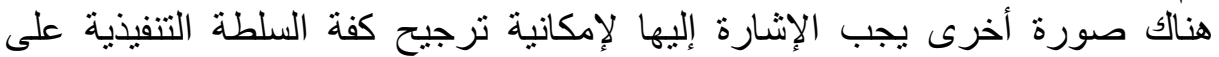

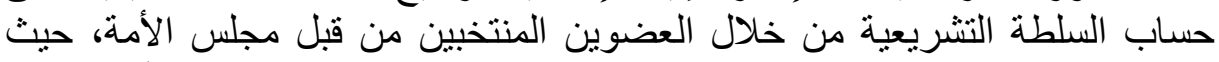

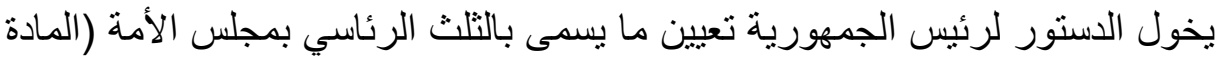

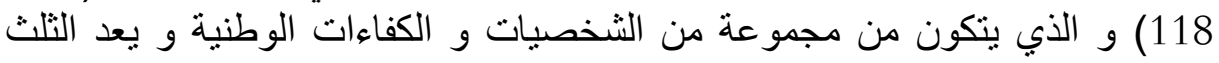

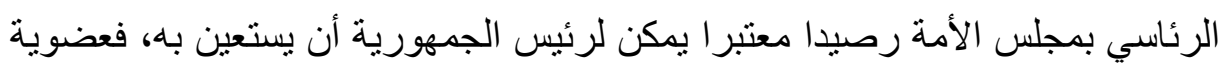

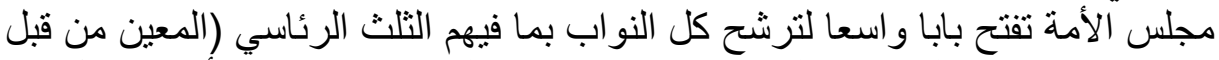

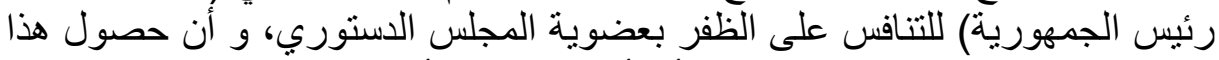

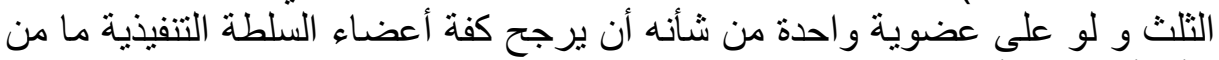

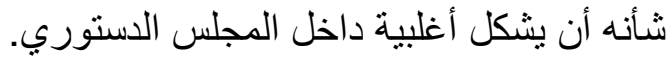
لذا كان من الأجدر أن تقتصر نرشيح الغيحات مجلس الأمة لعضوية المجلس الدستوري 
على الأعضاء المنتخبين و ليس المعينين (الثلث الرئاسي) حرصا على استقلال المجلس و سدا لباب نفوذ السلطة التنفيذية.

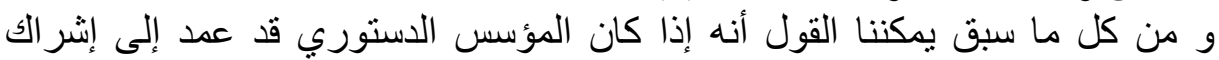

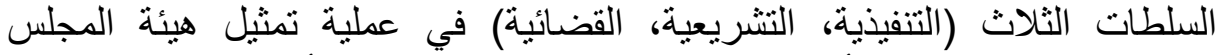
الاستوري بالتساوي إلا أنه لم يكرس ذللك بشكل مراع لمبدأ التوازن في طريقة

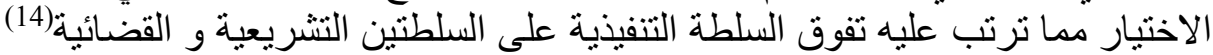

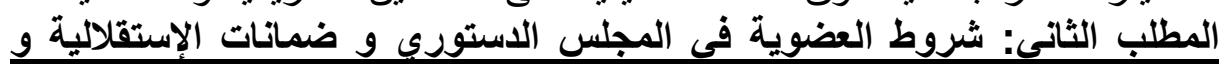
الحياد: لم يضع المؤسس الدستوري في دستور 1989 و التعديل الدستوري 1996، أدنى

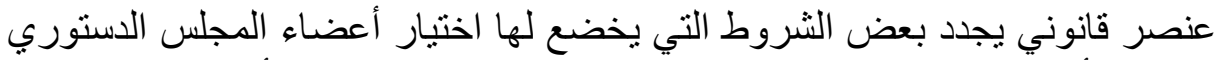

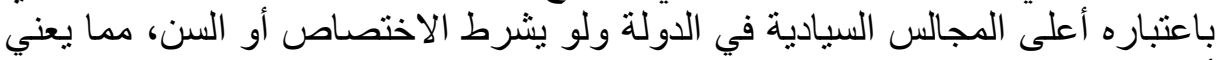

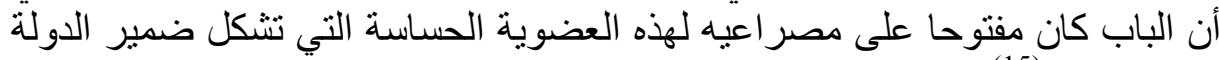

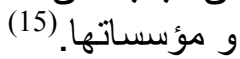
مما جعل المؤسس الاستوري الجزائري يتدارك هذا الأمر بإقراره جملة من الثروط

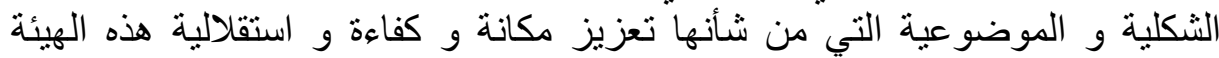

الفرع الأول: شروط العضوية في المجلس الاستوري:

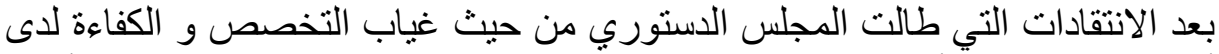

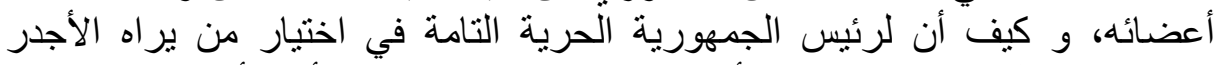

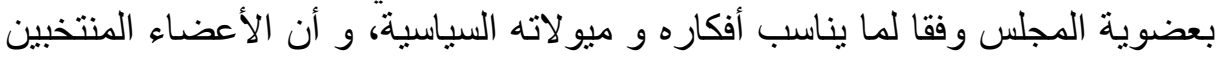

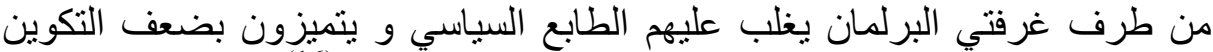

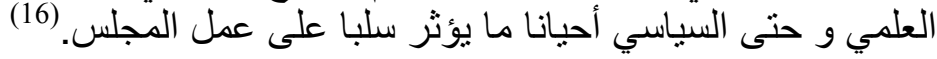

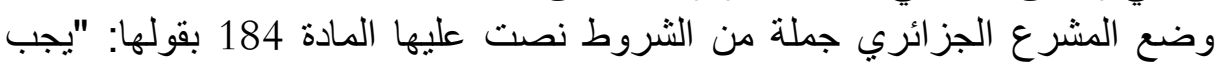
على أعضاء المجلس الدستوري المنتخبين أو المعينين ما يأتي:

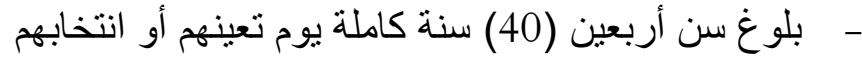

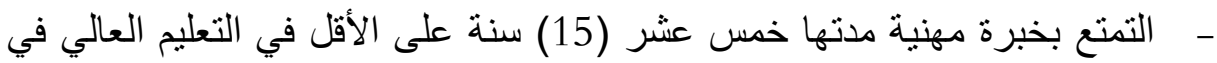

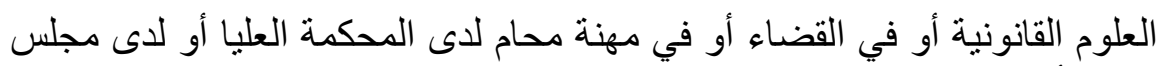

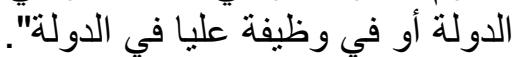

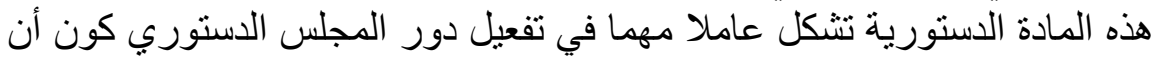

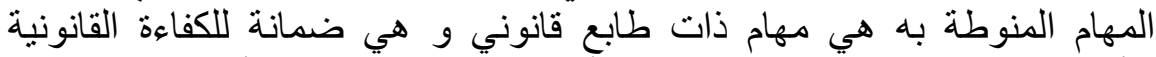
للأعضاء، وهو ما يمنح المجلس دورا أكثر فعالية على اعتى اعتبار أن مهمة المجلس

هي مهمة تقنية تتطلب خبرة و تخصص الئس دور التي المستوى في مجال القانون. (17)

هذا ما يتبادر في ذهن القارئ عند القراعة الأولية لنص هذه المادة لكن المتعمق في المادي

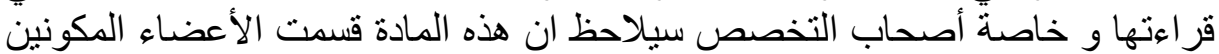
للفجلس الدستوري إلى فئتين: الفئة الأولى هي فئة القانونيين الذين يتمتعون بخبرة مهنية مدة 15 سنة في مجال

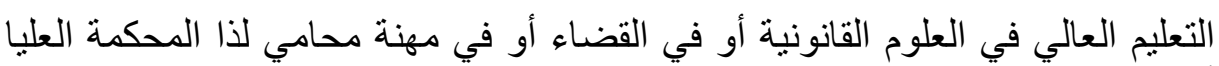
أو لاى مجلس الدولة الدي و هو ما يدعم عمل المجلس الدستوري بكون أعضائه ذوي خبرة قانونية مدعومة أكاديميا و عمليا على أرض الوغل الواقع.

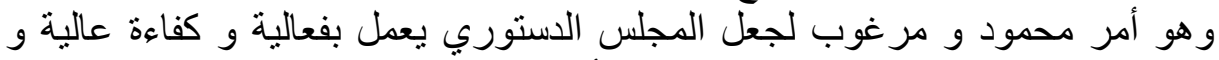
يضفي عليه الطابع القانوني القضائي لكن أضاف المؤسس الدستوري في نفس نفس نص 
هذه المادة عبارة: " أو في وظيفة عليا في الدولة".

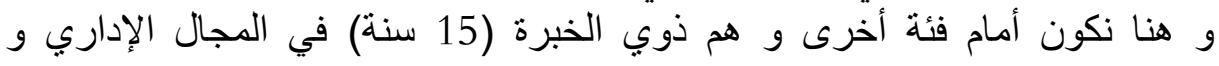

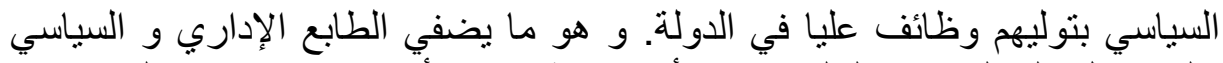

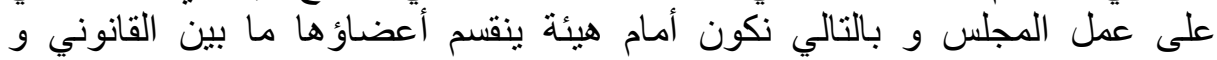

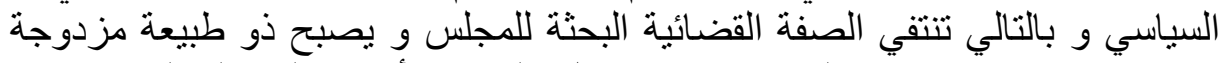

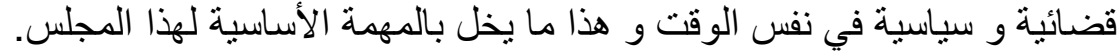

\section{الفرع الثانى: ضمانات حياد أعضاء المجلس الاستوري:}

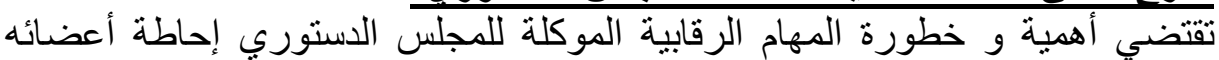

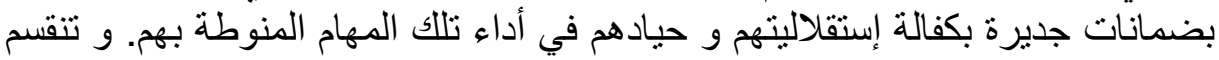

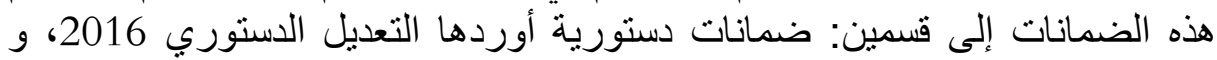

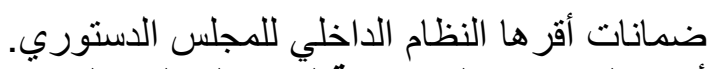

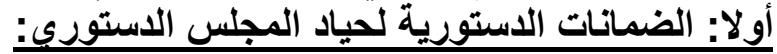

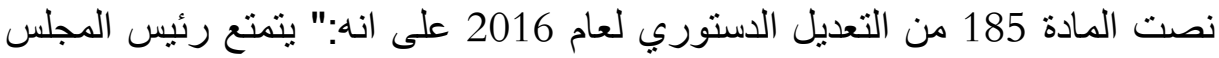

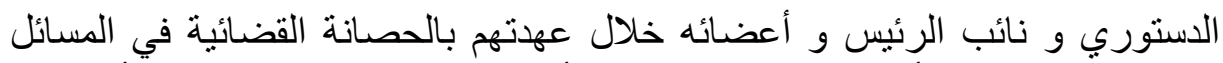

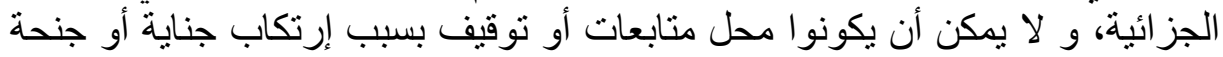

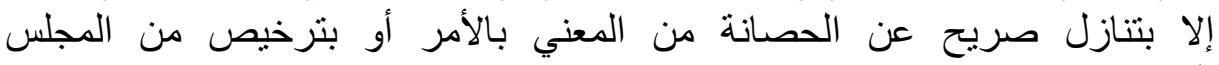

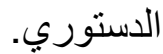

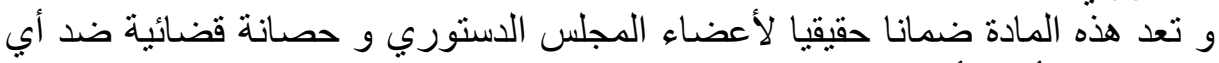

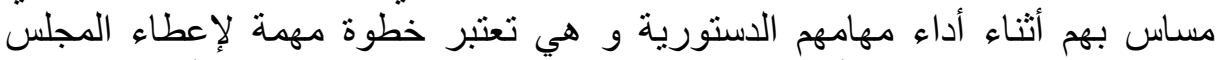

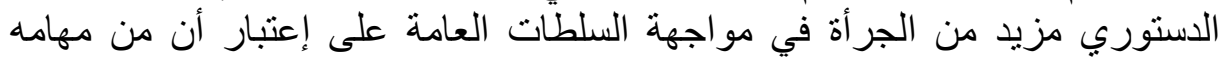

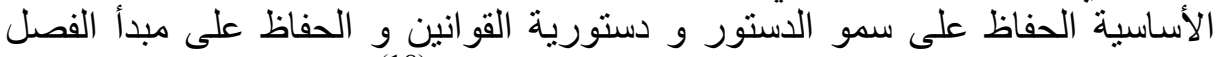

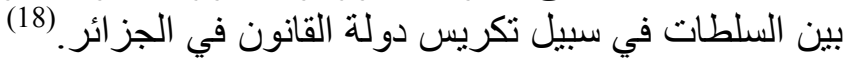

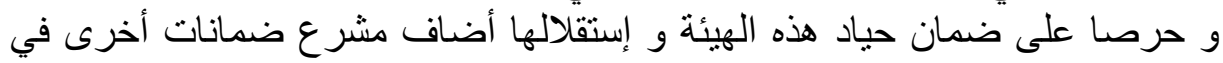

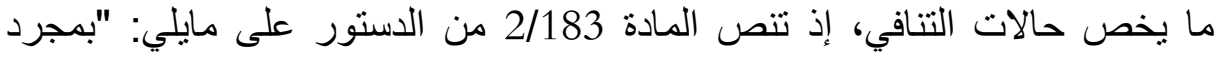

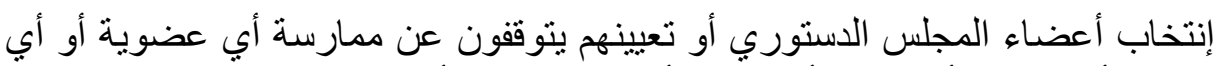

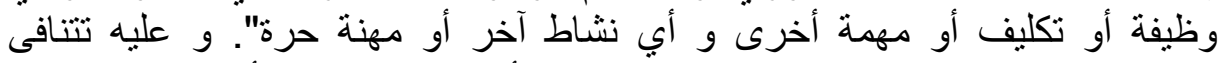

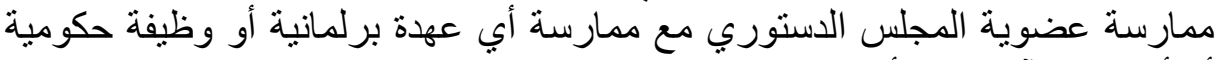

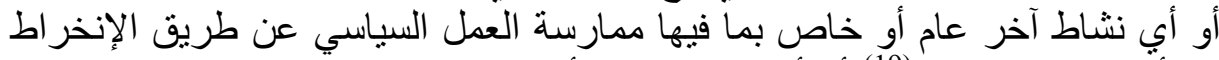

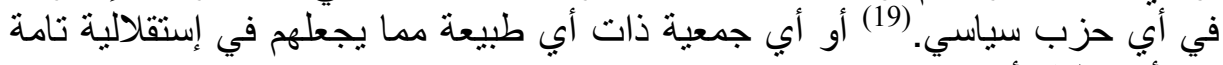

عن أب سلطة أو جهة سياسية مهما كان نوعها.

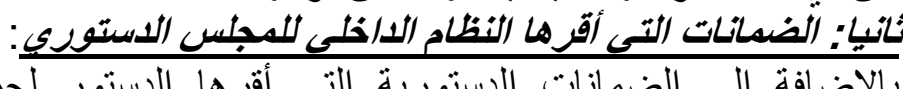

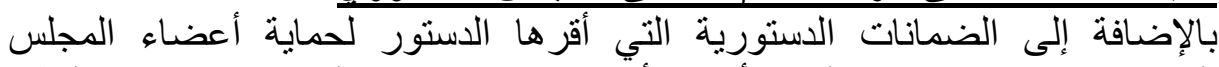

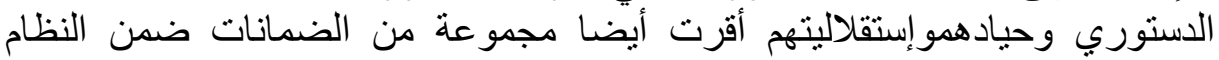

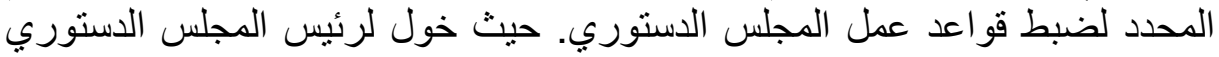

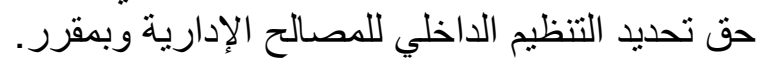

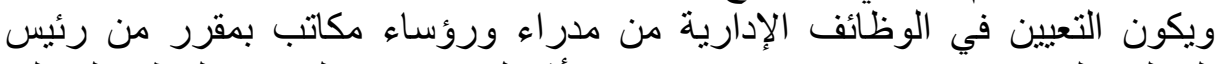

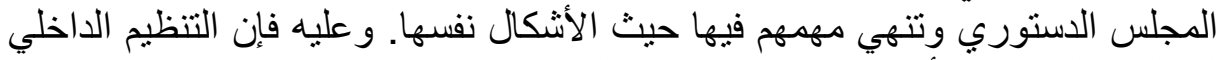

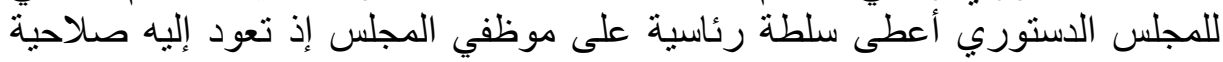
التعبين و الإعفاء من المهام. المئي أما في المجال التأديبي، يحظى المجلس الدستوري بإستقالية تامة إذ يمارس بنفسه 
السلطة التأديبية على أعضائه، وتشكل هذه الإستقلالية في المجال التأديبي ضمانة فعلية

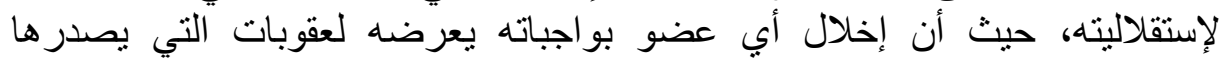

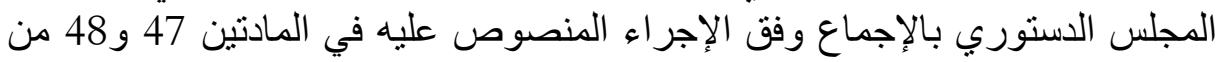

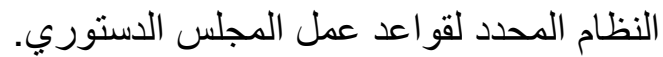

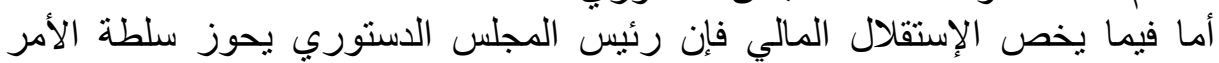

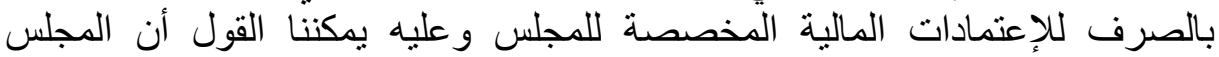

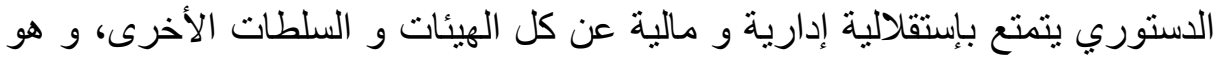

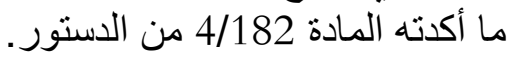

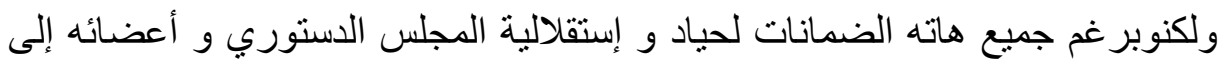

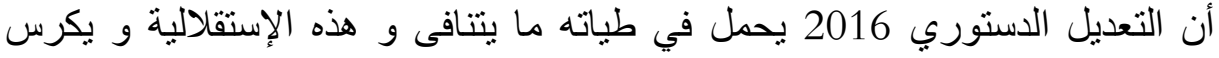

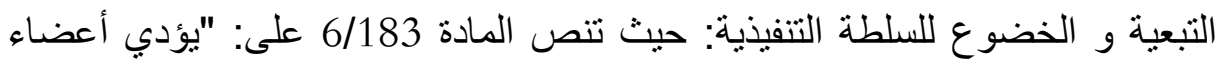

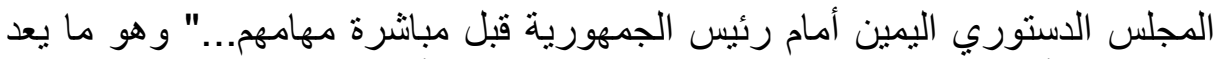
إخلال بمبدأ الإستقلالية و تبعية مباثرة سياسية و أدبية و و حتى قانونية لرئيس

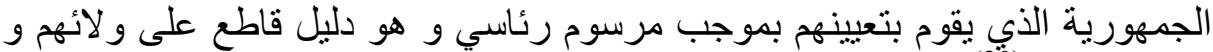
خضو عهم له. (20) والأنسب أن تؤدي اليمين أمام ممثلي السلطات الثناثة باعتبار المجلس متكون من ألناء أعضاء ينتمون إلى السلطات الثلاثة وليس للسلطة التتفيذية وحدها مما يعطي أعضائه

أكثر مصداقية.

\section{III}

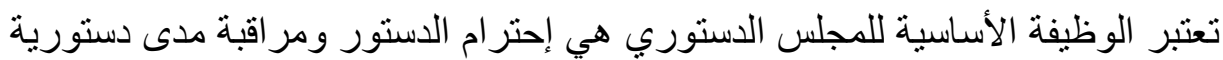

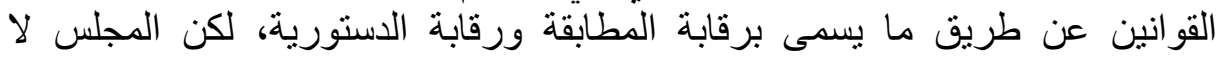

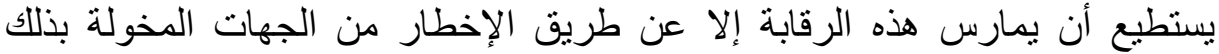

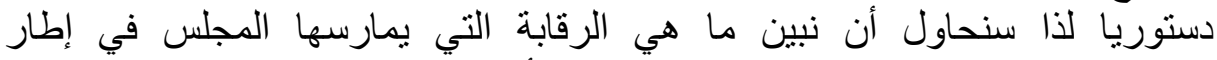

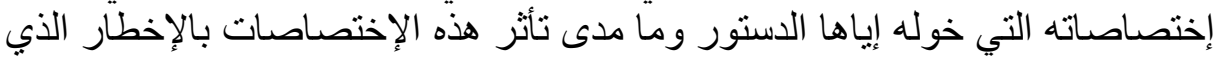

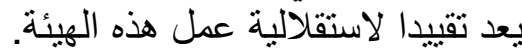
المطلب الأول: إختصاصات المجلس الإنة الديتوري:

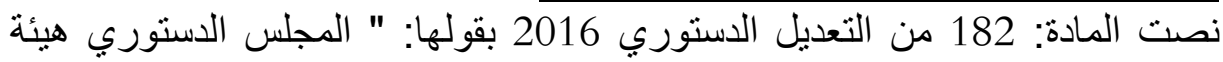

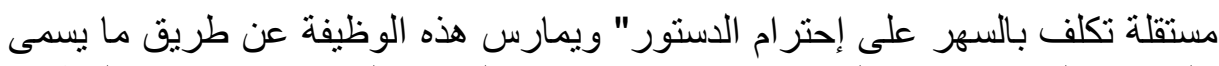

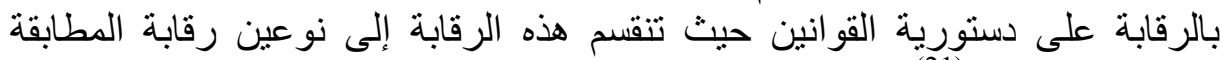
ورقابة الدستورية. ولكل منها مجال معين حددنه المادة 186 من التعديل الدستوري 2016 كما يختص المجلس في الرقابة على عمليات الإستفتاء و الإنتخابات الرئاسية و الإنية التشريعية

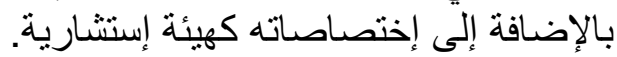

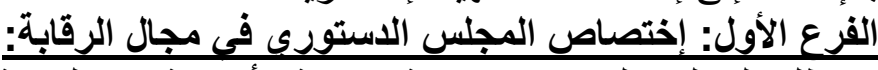

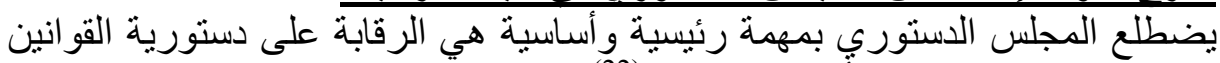
والحرص على مطابقتها لأحكام الدستور . (22)

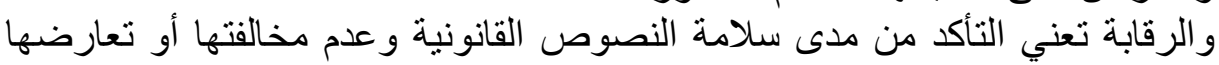
مع المبادئ الدستورية المقررة.

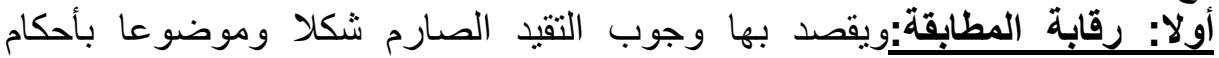
النصوص الدستورية، وتكون رقابة رقابة المطابقة على القوانين العضوية وعلى النظام الداخلي لكل من غرفتي البرلمان. رقابة مطابقة القوانين العضوية: العرلية 
نصت المادة 2/141 من التعديل الدستوري على: "يخضع القانون العضوي لمراقبة

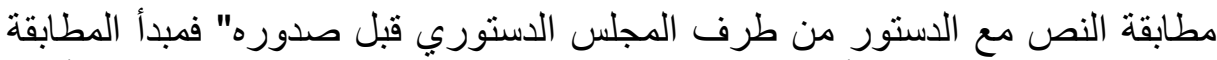

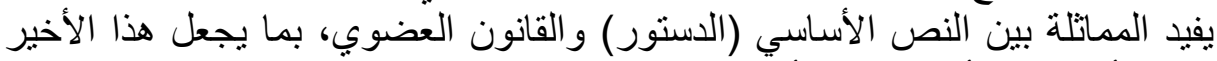

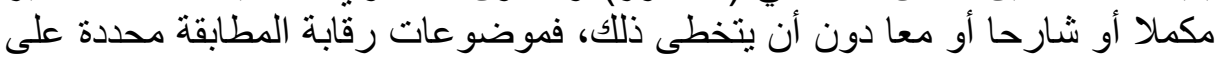

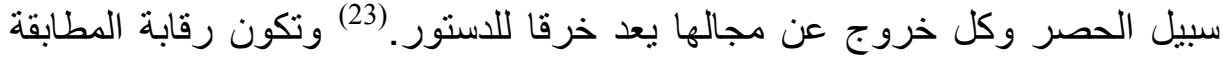
على القو انين العضوية وجوبية وقبلية.

\section{رقابة مطابقة النظام الداخلى لغرفتى البرلمان:}

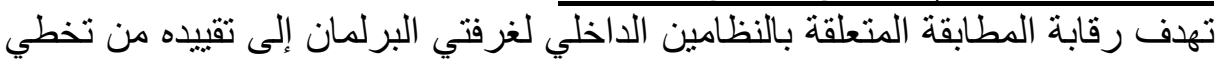

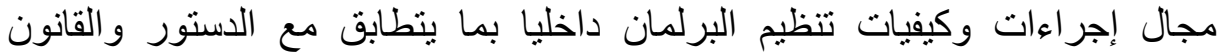
العضوي الذي يحدد تنظيم المجلسين المشكلين له و عملهماوكذا العلاقات الوظينات الوظيفية

تتص المادة 3/186 من التعديل الدستوري 2016 على: كما يفصل المجلس الدستوري

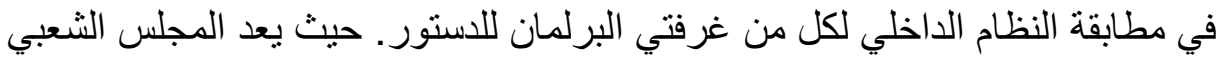

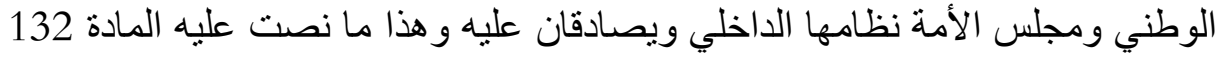

بقولها: "يعد المجلس الثعبي الوطني ومجلس الأمة نظامها الداخلي ويصادقان عليه".

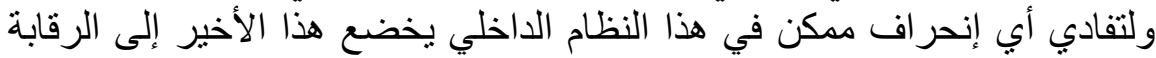

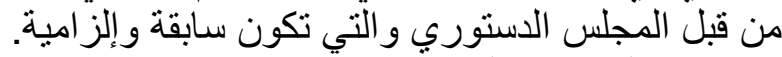

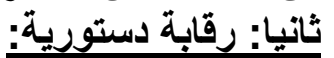

تتعلق الرقابة الدستورية بمعاهدات واتية والقوانين العادية و التنظيماتوتكون إختيارية بناءا

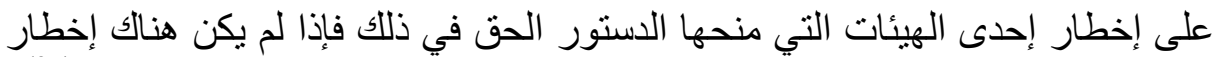

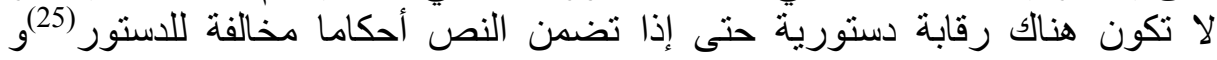
يفصل المجلس الدستوري بر أي في دستورية المعاهدات و القوانين دانين و التنظيمات و هذا

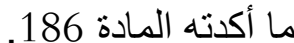

المعاهدات: تتص المادة 190 من التعديل الدستوري 2016 على: "إذا ارتأى المجلس

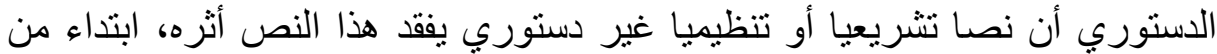

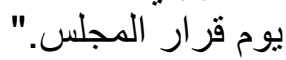

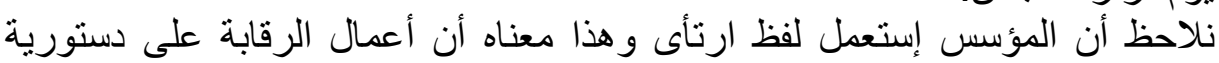
المعاهدات تكون عن طريق رأي قبل التصديق إنيق عليها من قبل رئيس التئ الجمهورية.

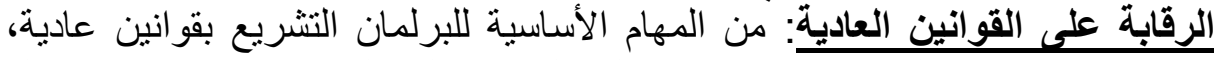

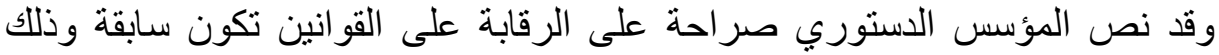

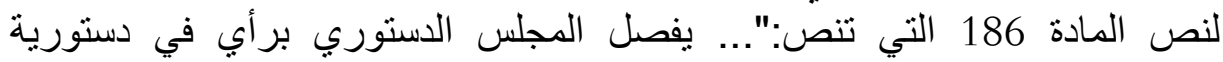

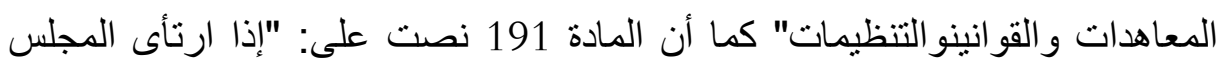

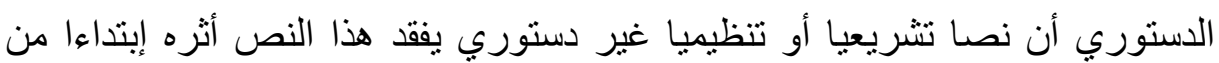

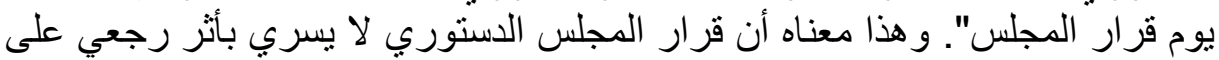

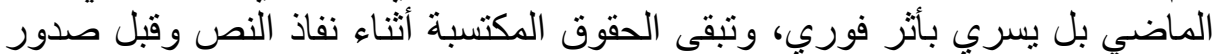

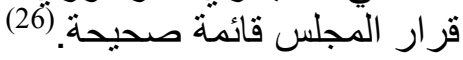

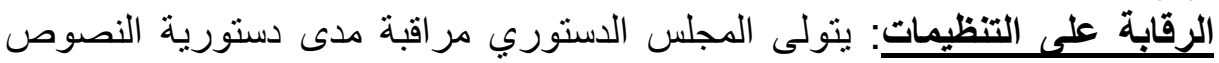

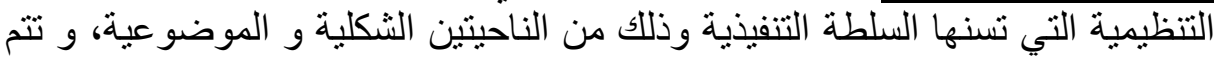

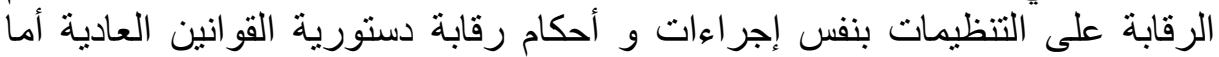

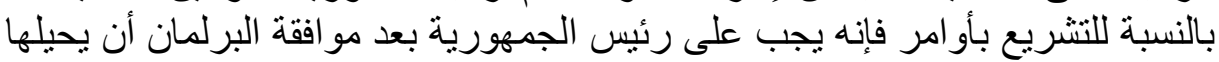


إلى المجلس الدستوري ليتولى مر اقبتها.

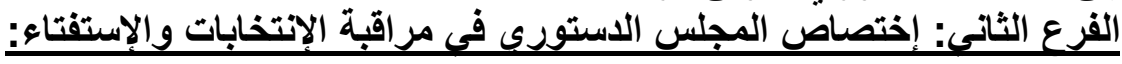

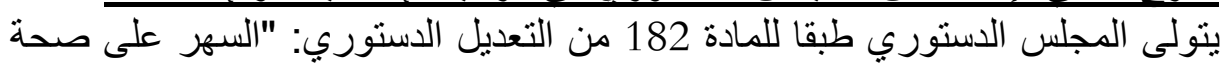

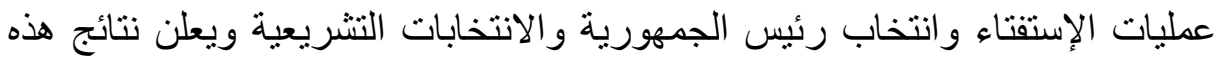

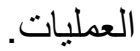
وينظر في جوهر الطعون التي يتلقاها حول النتائج المؤقتة للانتخابات الرئاسية والانتخابات التشريعية ويعلن النتائج النهائية بكل العمليات المنصول النصوص عليها.

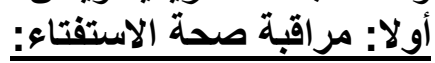

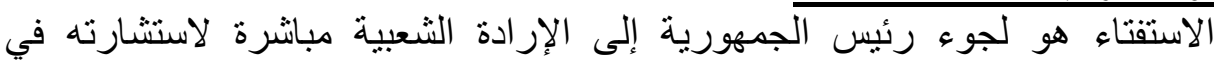

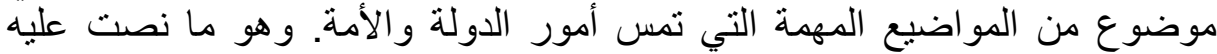

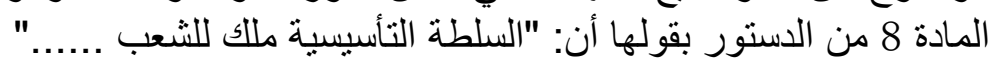
يمارس الثعب هذه السيادة أيضا عن طريق الاستفتاء وبواسطة ممثليه المنتخبين.

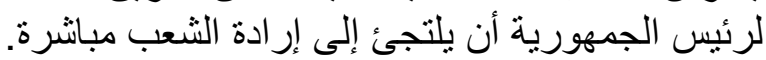
ويمارس المجلس الدستوري الرقابة على صحة الاستفتاءات. طبقا للمو اد 44 إلى 48

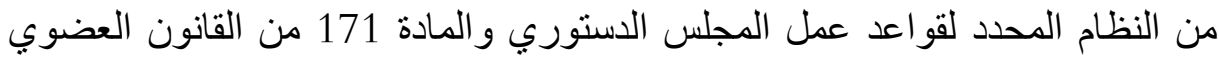

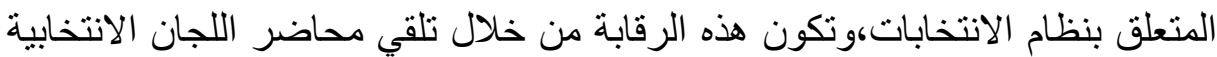
الو لائية، كما يتلقى الطعون المتعلقة بعملية الاستفتاء وبعد دراسة التانة هذه الاحتجاجات، يعلن المجلس الدستوري النتائج النهائية.

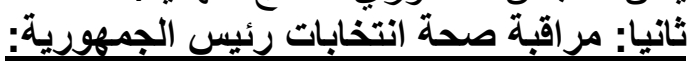

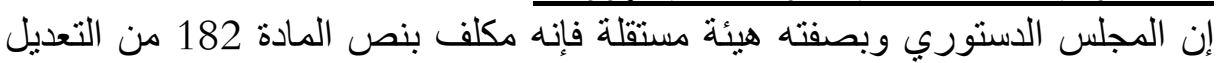

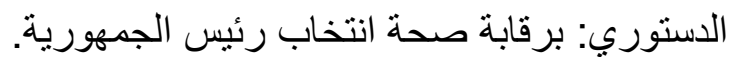
وتكون الرقابة على الانتخابات الرئاسية من أنسية أول مرحلة وهية وهي الترشح و وإلى غاية آخر

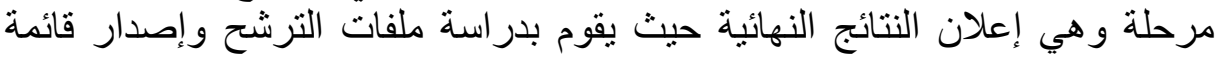

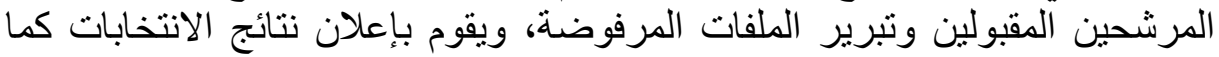

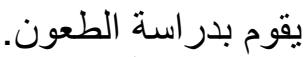

ثالثا: مراقبة الانتخابات التشريعية:

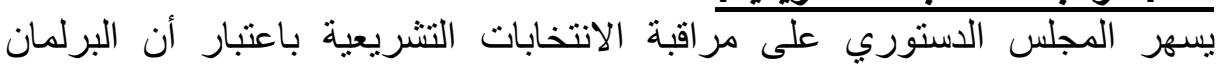

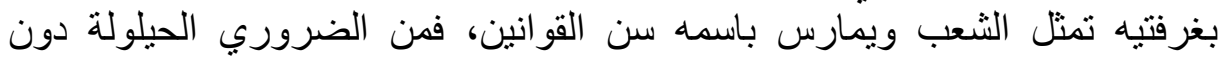

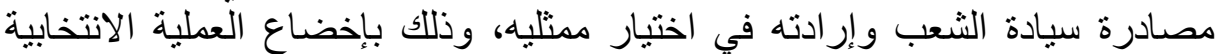

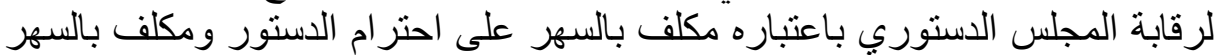
على صحة الانتخابات التشريعية وإعلان نتائجها بموجب التباري المادة 182 من التعديل

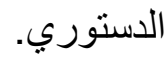
المطلب الثثانى: مدى تأثز اختصاصات المجلس الاستوري بإجراء الإخطار:

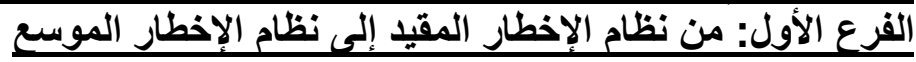

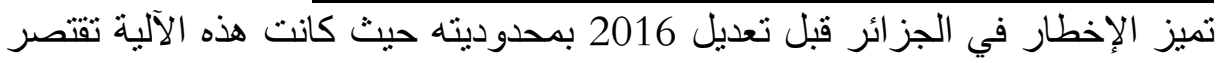
على عدد محدد من الأشخاص أو الهيئات المخولة بممارسته، حيث نصت فئ المادة 166

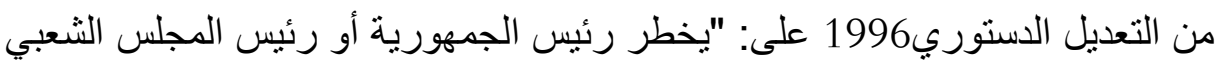

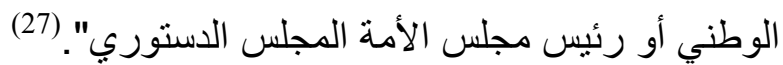

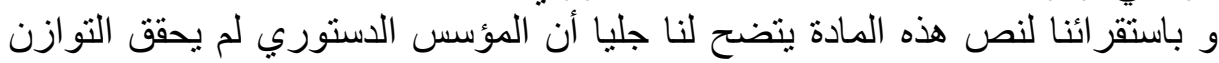

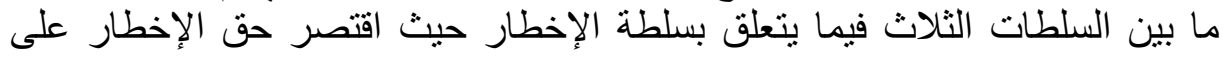
رئيس الجمهورية ممثلا للسلطة التنفيذية و رئيس غرفية التئي البرلمان ممثلين للسلطة

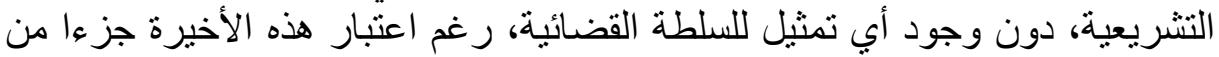


تشكيلة المجلس الدستوري إلا أنها لا تمتلك حق إخطار الأمر الذي له بالغ الأثر على التى الته

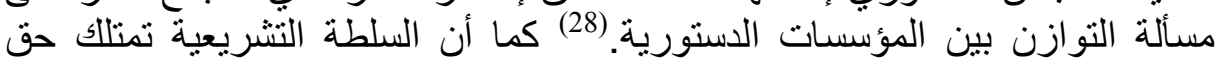

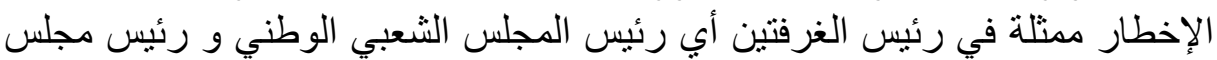

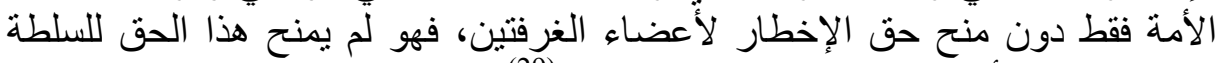

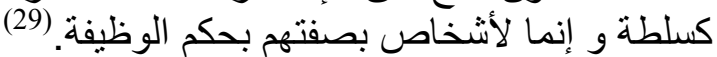

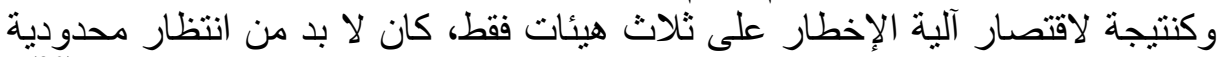

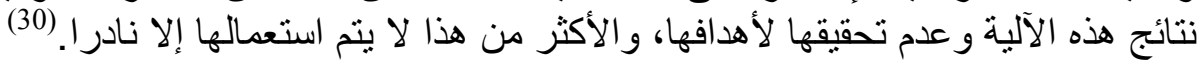
وقد استدرك المؤسس الجزائري هذا الأمر من خلال التعديل الدستوري 2016 أين

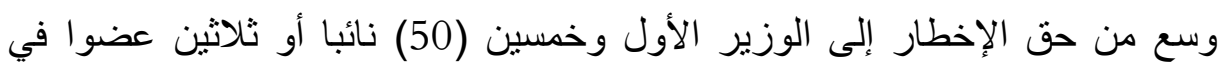

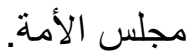
حيث نصت المادة 187 منه على: "يخطر المجلس الدستوري رئيس الجمهورية أو رئيس مجلس الأمة أو رئيس المجلس الثعبي الوطني أو والوزير الأولى الونس كما يمكن إخطاره من خمسين (50) نائبا أو ثلاثين عضوا الأني في مجلس الأمة".

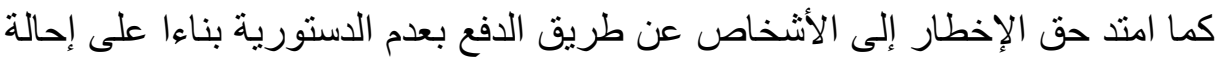
من المحكمة العليا أو مجلس الإلى الدولة الألة (31) و هو ما نصت عليه المادة 188 من التعديل الدستوري لسنة 2016 بقولها: "يمكن

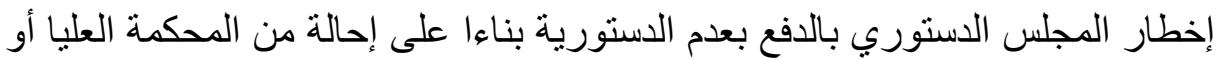

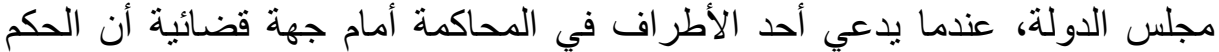

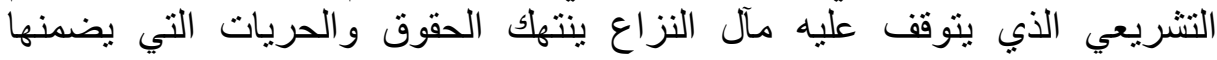

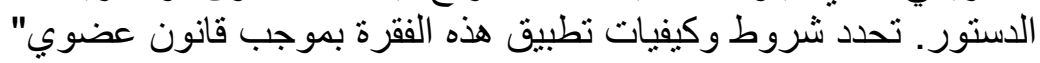

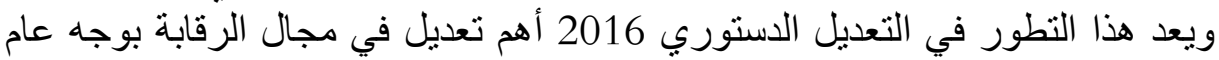
و الرقابة على دستورية القوانين بوجه خاص، حيث فئ فتح المؤسس الاستوري الإخطار

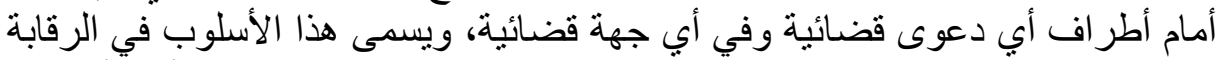

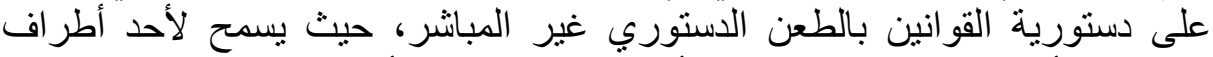

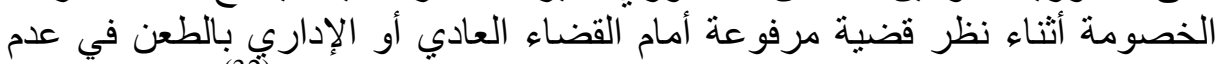

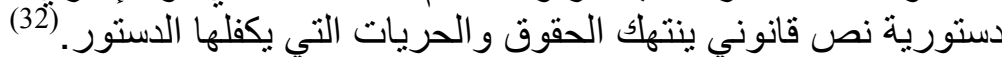
الفرع الثانى: دور الإخطار في تقييد عمل المجلس الدستوري وتكريس تبعيته

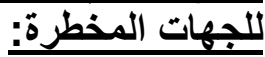
إن تحريك الرقابة الدستورية من قبل المجلس الدستوري لا يكون تلقائيا و إنما يتم ذلك الكه

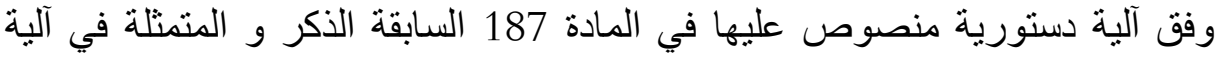

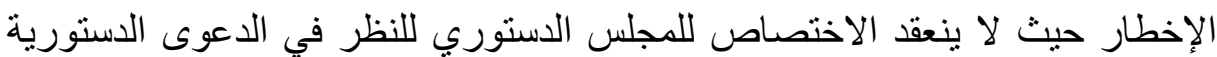

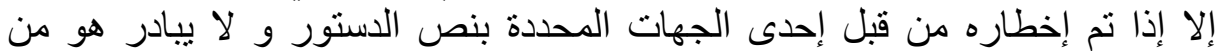

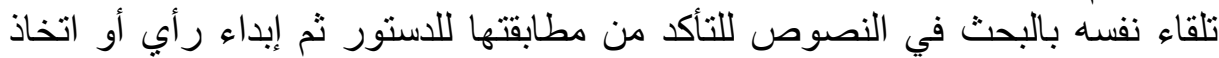

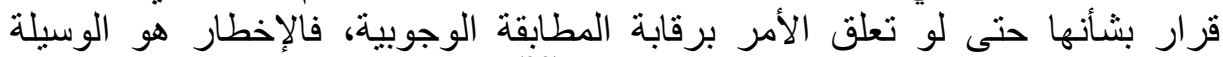
الوحيدة لتحريك الرقابة على لونى دستورية القو انين.

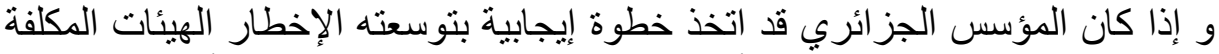

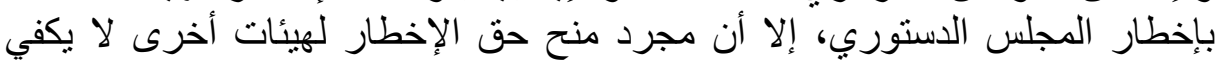

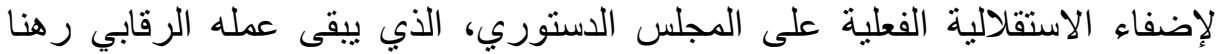

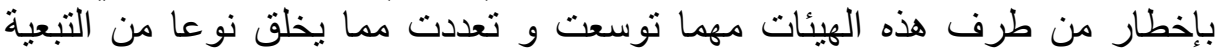

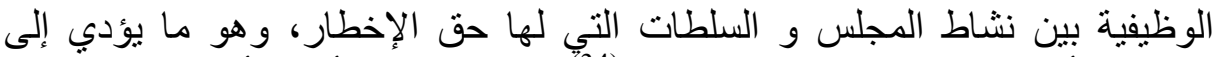

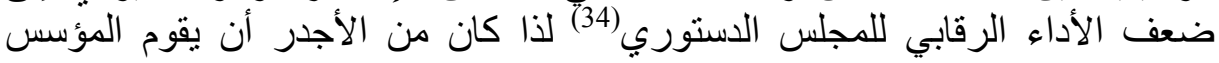


الدستوري بتكريس سلطة الرقابة الدستورية بصورة تلقائية بأن يراقب المجلس الدستوري مدى دستورية القوانين و المعاهدات و التنظيمات من تلقاء نفسه دون

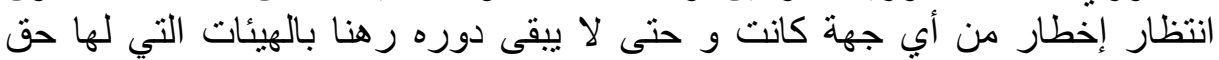

سعى المؤسس الجز ائري من خلال التعديل الدستوري 2016 إلى تعزيز دور المجلس الدستوري كهيئة رقابية على دستورية القوانين من خلال توسعة تشكيلة المجلس من 9 أعضاء إلى 12 عضوا، كما حاول المؤسس الدستوري تكريس مبدأ التوازن بين السلطات الثلاثة من خلال تساوي حصص التمثيل داخل المجلس بأربعة أعضاء لكل

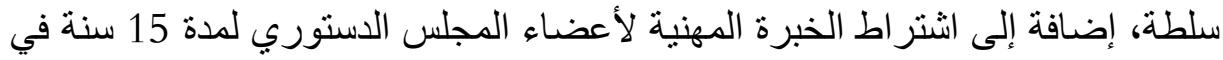

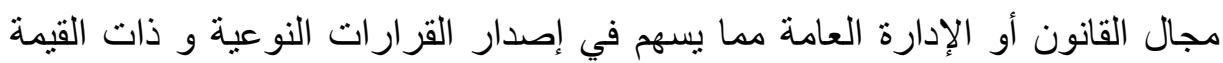

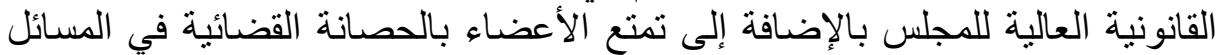
الجنائية مما يجعلهم في منأى من المتابعات القضائية و لإلية بالتالي هو نوع من الحماية لهم

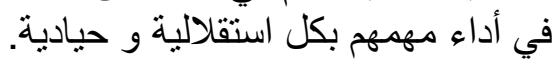
كما أن المؤسس الدستوري قام بتوسيع سلطة الإخطار إلى هيئات جديدة (الوزير

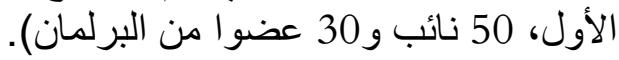

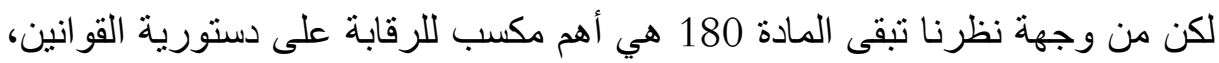

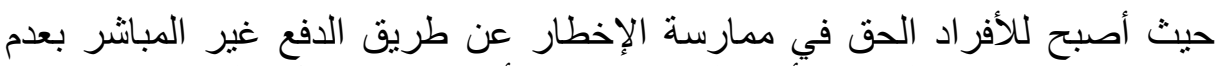

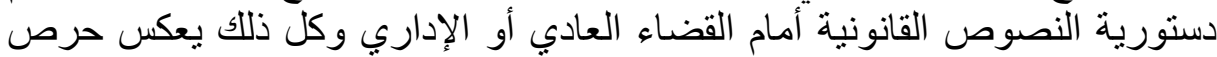

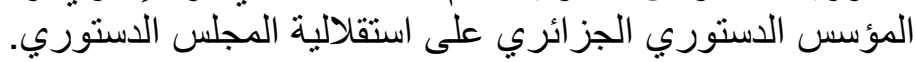

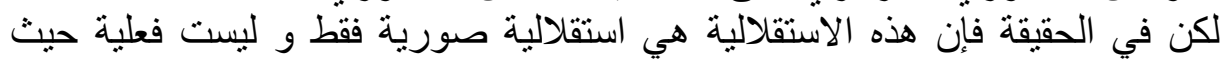
كرس المؤسس الدستوري تفوق السلطة التنفيذية و تبعية المجلس لها لهائة خاصيّة بإعطاء

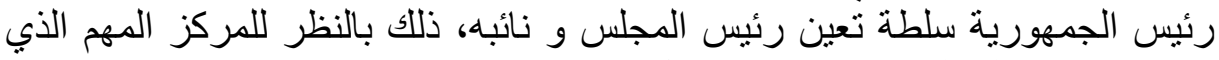

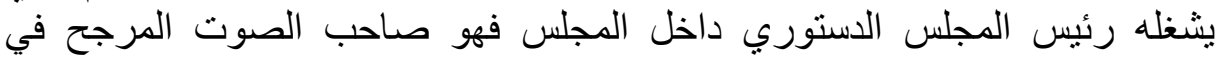
قرارات المجلس، و تبقى النقطة السوداء في عمل المجلس و التي تكرس عدم استقلاله

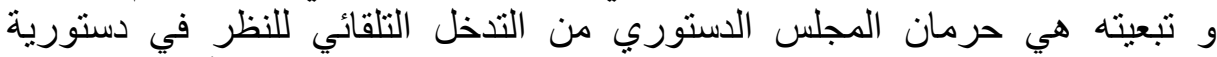

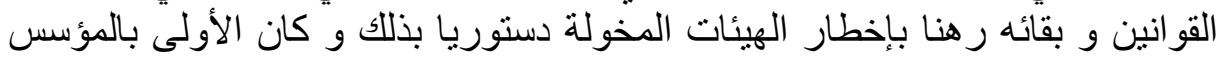

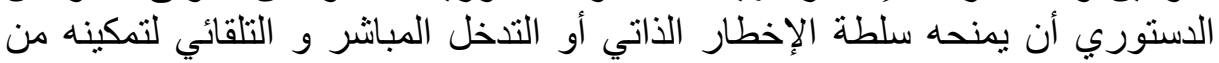
ممارسة دوره الرقابي بكل استقلالية و حيادية. 


\section{• المصاجع القاتونية:}

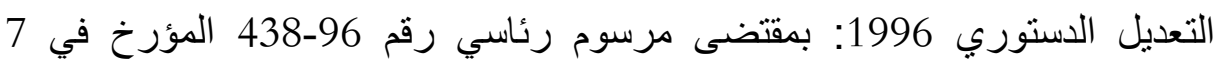
ديسمبر 1996 منشور في الجريدة الرسمية للجمهورية الجزئية رئرية عدد 76 المؤرخ 8 ديسمبر 1996. -التعديل الدستوري 2016 الصادر بموجب القانون رقم 01/16 المؤرخ في 6 مارس 2016 والصادر في الجريدة الرسمية العدد 14 الصادرة بتاريخ 7 مارس 2016. الكتب:

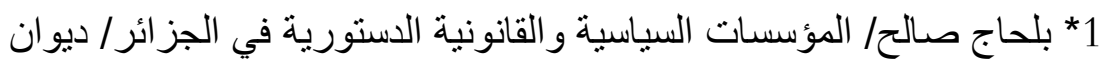

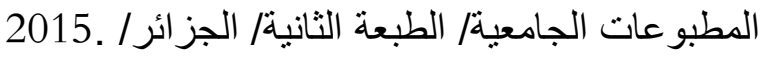

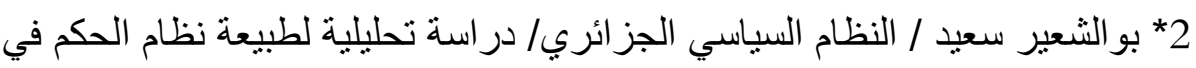

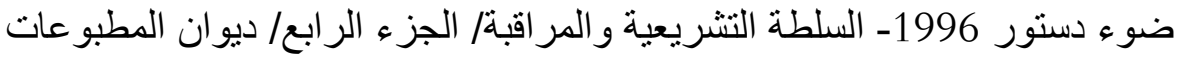

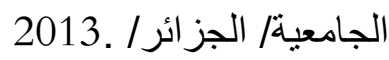
3* رابحي احسن / الوسيط في القانون الدستوري/ دار هومة/ الطبعة الثانية /الجزائر .$/ 2014$ 4* غريبي فاطمة الزهراء / أصول القانون الدستوري و النظم السياسية/ دار الخلود

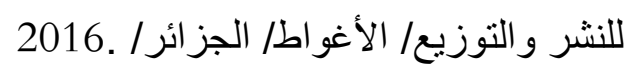

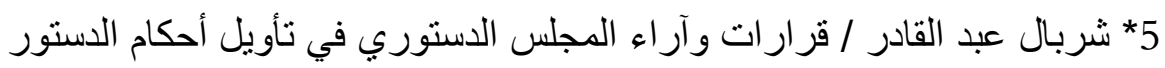

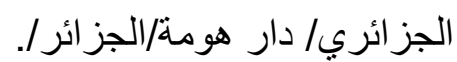
6* لعشب محفوظ / التجربة الدستورية في الجزائر / الدطبعة الحديثة للفنون المطبعية

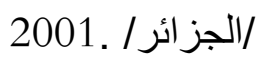
7* مسر اتي سليمة / نظام الرقابة على دستورية القو انين في الجزائر / دار هومة/

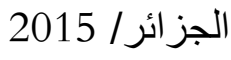

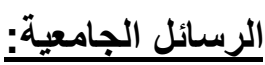

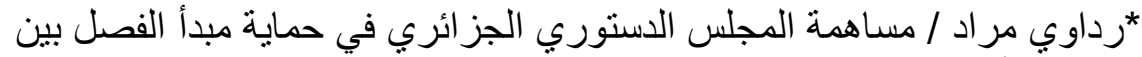

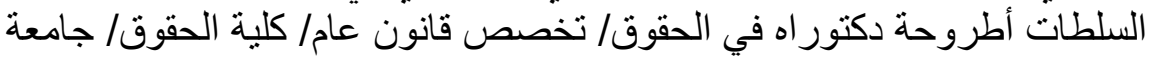

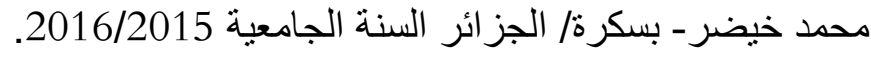

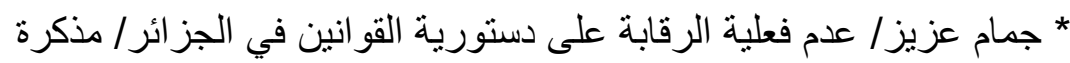

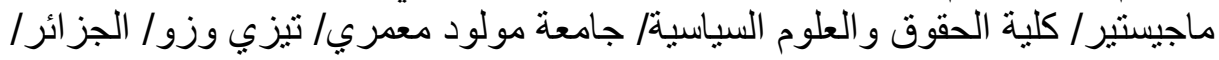

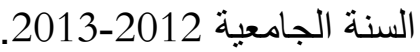




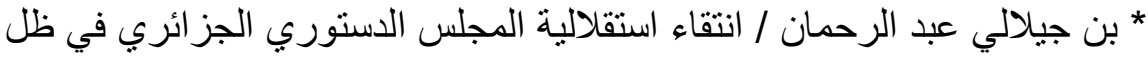

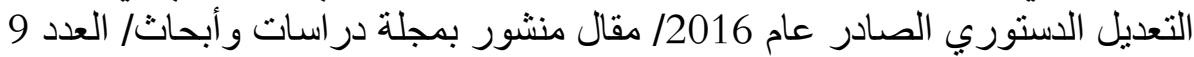
سبتمبر 2017.

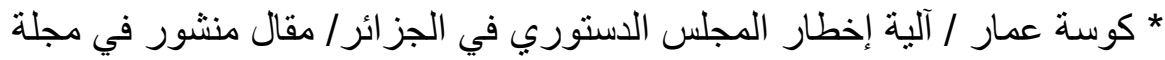

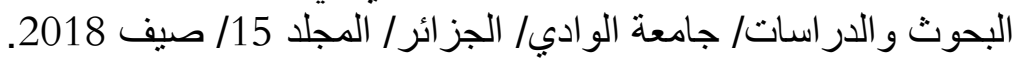

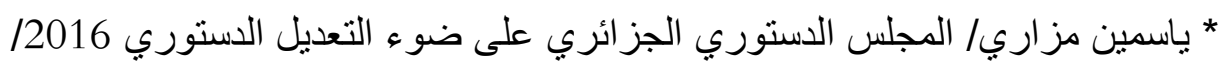

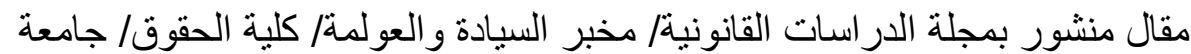

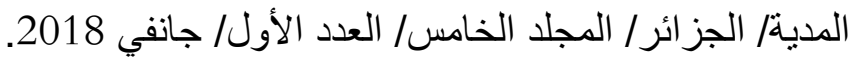
ل موامش

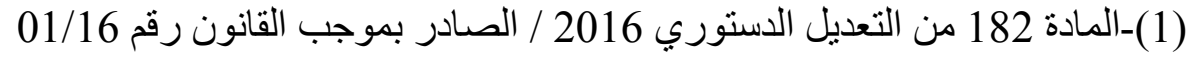
المؤر خ في 06 مارس 182016 من المعادي الصنادر في الجريدة الرسمية العدد 14 الصادرة بتاريخ

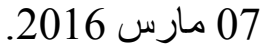

(2)- رداوي مر اد / مساهمة المجلس الدستوري الجز ائري في حماية مبدأ الفصل بين

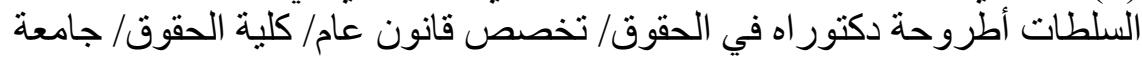

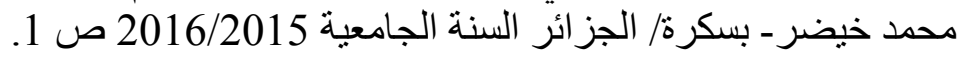
(3)- محفوظ لعشب/ التجربة الدستورية في الجز ائر / المطبعة الحديثة للفنون المطبعية

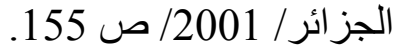

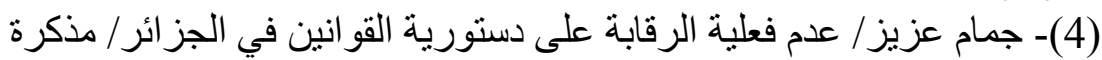

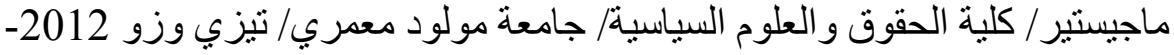

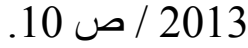

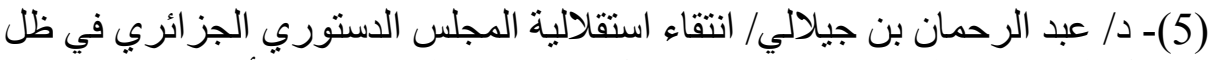

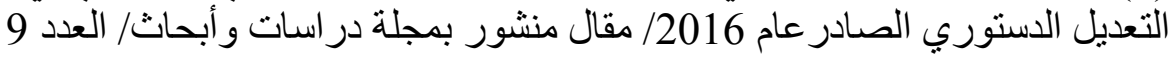

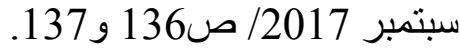

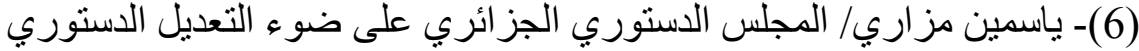

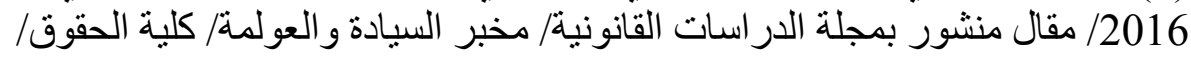

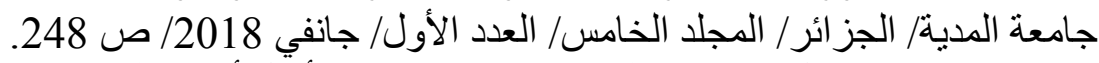

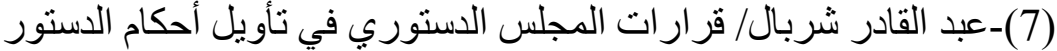

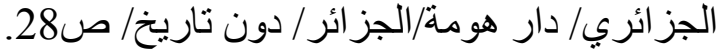

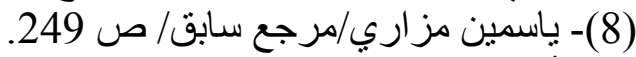

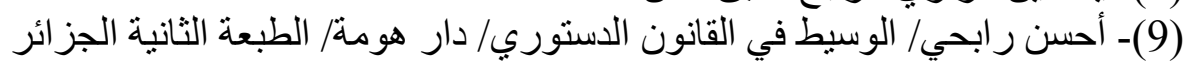

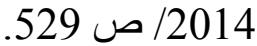

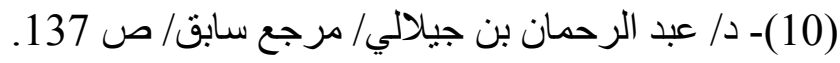

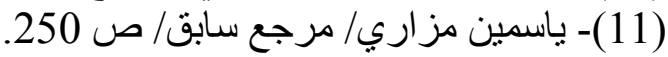

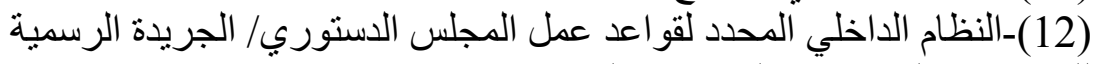

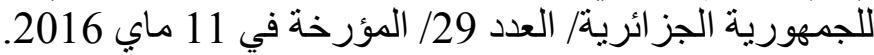

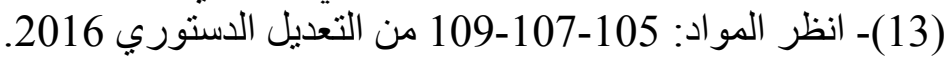

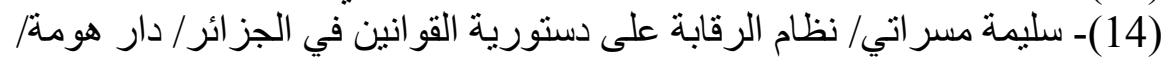

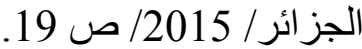

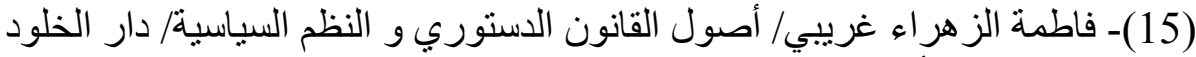

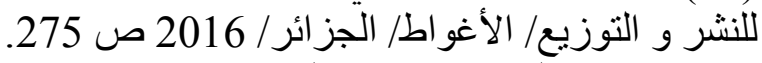

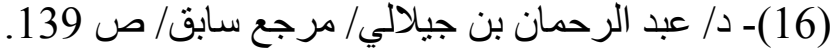
(17)- د/ عبد الرحمان بن جيلالي/ مرجع سابق/ صر د 139 


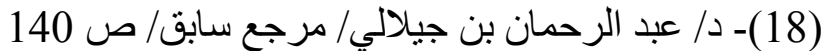

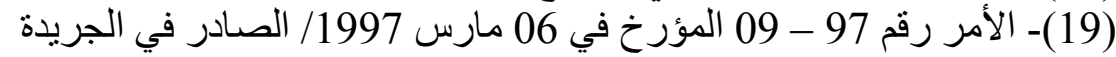

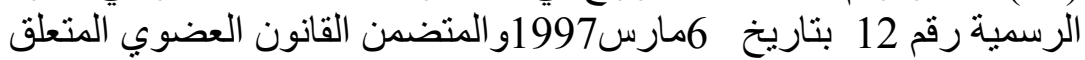

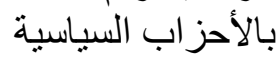

(20)- د/ عبد الرحمان بن جيلالي/ مرجع سابق/ ص ص الز 141.

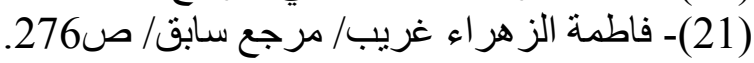

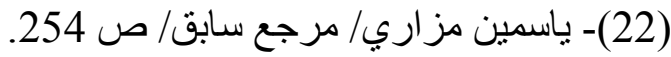

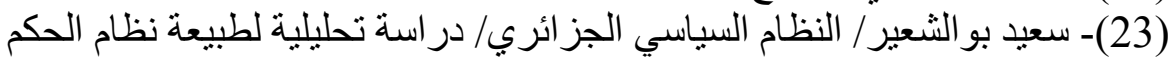

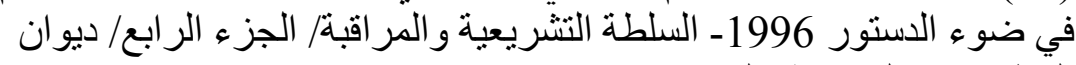

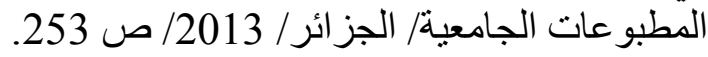

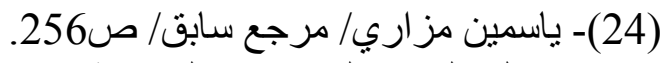

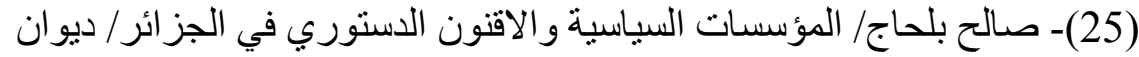

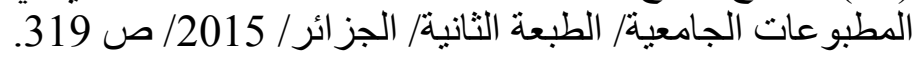

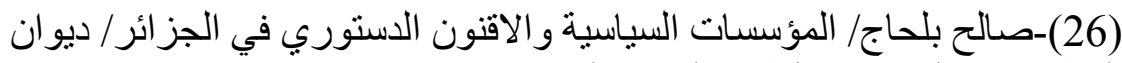

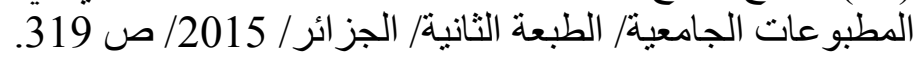

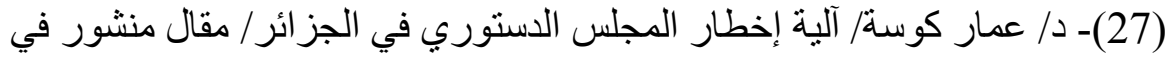

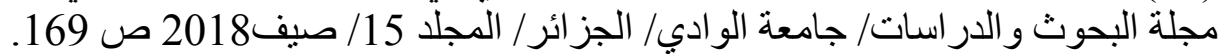

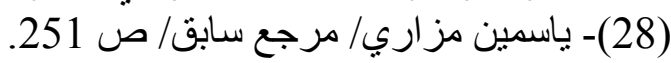

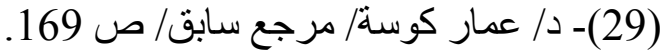

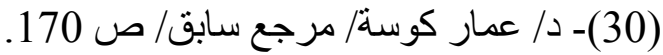

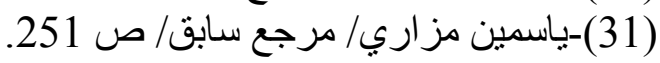

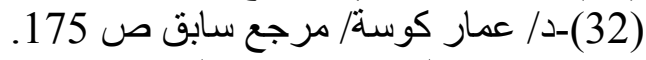

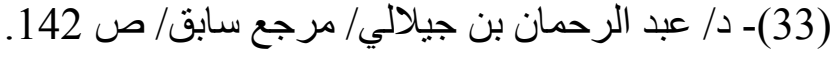

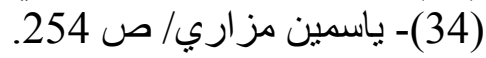

